\title{
Adaptive Fuzzy Wavelet NN Control Strategy for Full Car Suspension System
}

\author{
Laiq Khan, Rabiah Badar and Shahid Qamar \\ Department of Electrical Engineering, \\ COMSATS Institute of Information Technology, Abbottabad \\ Pakistan
}

\section{Introduction}

In the last few years, different linear and non-linear control techniques have been applied by many researchers on the vehicle suspension system. The basic purpose of suspension system is to improve the ride comfort and better road handling capability. Therefore, a comfortable and fully controlled ride can not be guaranteed without a good suspension system. The suspension system can be categorized as; Passive, Semi-active and Active.

The passive suspension system is an open loop control system consisting of the energy storing (spring) and dissipating element (damper). The passive suspension performance depends on the road profile, controlling the relative movement of the body and tires by using various kinds of damping and energy dissipating elements. Passive suspension has considerable restriction in structural applications. The features are resolved by the designers with respect to the design objectives and the proposed application. All the ongoing research in this area mainly caters the following issues to improve the suspension control;

- minimize the effect of road and inertial disturbances, on human body, caused by cornering or braking.

- minimize the vertical car body displacement and acceleration.

- good control on all the four wheels of the car for their optimal contact with road.

All the above objectives lead to rapidly changing operating conditions and the passive suspension system is not as efficient to cope with them by adapting its parameters, simultaneously. So, there would always be a compromise between comfort and safety for passive suspension system.

Semi-active suspension system consists of a sensor that identifies bumps on the road and motion of the vehicle and a controller that controls the damper on each wheel. The semi-active suspension can respond to even small variations in road area and cornering. It offers quick variations in rate of springs damping coefficients. This suspension system does not give any energy to the system but damper is changed by the controller. The controller resolves the rank of damping based on control approach and automatically changes the damper according to the preferred levels. Actuator and sensors are attached to sense the road profile for the control input. The adaptive fuzzy controller for semi-active suspension systems was presented by 
(Lieh \& Li, 1997) which shows only the acceleration of the vehicle compared to the passive suspension.

On the other hand, active suspension consists of actuator. The controller drives the actuator, which depends on the proposed control law. The active suspension system gives the freedom to tune the whole suspension system and the control force can be initiated locally or globally depending on the system state. The active suspension systems provide more design flexibility and increase the range of achievable objectives. The active suspension passenger seat is proposed by (Stein \& Ballo, 1991) for off-road vehicles. Also, the passenger suspension seat was considered by (Nicolas et al., 1997) in their control technique to improve ride comfort. Various control techniques such as optimal state-feedback (Esmailzadeh \& Taghirad, 1996), model reference adaptive control (Sunwoo et al., June 1991), backstepping method (Lin \& Kanellakopoulos, 1997), fuzzy control (Yoshimura et al., 1999) and sliding mode control (Yoshimura et al., 2001) have been presented in the last few years for optimized control of the active suspension system.

In order to examine these suspension systems, three types of car model have been introduced in the literature; Quarter car model, Half car model and Full car model. In car modeling, quarter car model is the simplest one. Many approaches on quarter car suspension systems have been carried out by (Hac, 1987; Yue et al., 1988) but do not reveal robustness of the system. The robustness of quarter-car suspension system based on stochastic stability has been presented by (Ray, 1991) but this technique needs large feedback gains and an appropriate phase must be chosen. The best performance estimations of variable suspension system on a quarter car model are observed by (Redfield \& Karnopp, 1988). Various linear control techniques are applied on a quarter car model in (Bigarbegian et al., 2008) but did not give any information for large gain from road disturbance to vehicle body acceleration. The dynamic behavior and vibration control of a half-car suspension model is inspected by different researchers in (Hac, 1986; Krtolica \& Hrovat, 1990; 1992; Thompson \& Davis, 2005; Thompson \& Pearce, 1998).

The active control of seat for full car model is examined by (Rahmi, 2003). Some control approaches have been examined to minimize the vertical motion, roll and also the chassis motion of vehicle by (Barak \& Hrovat, 1988; Cech, 1994; Crolla \& Abdel-Hady, 1991). The PID controller is applied on active suspension system by (Kumar, 2008). The combined $\mathrm{H}_{\infty}$ controller with LQR controller on an active car suspension is given by (Kaleemullah et al., 2011), but this controller requires the frequency characterization of the system uncertainties and plant disturbance, which are usually not available. An experimental 1-DOF microcomputerized based suspension system was presented by (White-Smoke, 2011), using actuator force as control input. However, the extension of this model to other practical models is not straightforward.

Fuzzy logic control has been utilized widely for the control applications. Such a control approach has the definite characteristic of being able to build up the controller without mathematical model of the system. Therefore, it has been employed to control active suspension systems (Hedrick \& Butsuen, 1990; Hrovat, 1982; Meller, 1978; Smith, 1995).

In (Nicolas et al., 1997), the authors used a fuzzy logic controller to increase the ride comfort of the vehicle. A variety of simulations showed that the fuzzy logic control is proficient to give a better ride quality than other common control approaches for example, skyhook control (Ahmadian \& Pare, 2000; Bigarbegian et al., 2008). (Lian et al., Feb. 2005) proposed a fuzzy 
controller to control the active suspension system. The fuzzy control for active suspension system presented by (Yester \& Jr., 1992) considers only the ride comfort. (Rao \& Prahlad, 1997) proposed a tuneable fuzzy logic controller, on active suspension system without taking into account the nonlinear features of the suspension spring and shock absorber, also, the robustness problem was not discussed. The neural network control system applied on active suspension system has been discussed by (Moran \& Masao, 1994) but does not give enough information about the robustness and sensitivity properties of the neural control towards the parameter deviations and model uncertainties. Also, sliding mode neural network inference fuzzy logic control for active suspension systems is presented by (Al-Holou et al., 2002), but did not give any information about the rattle space limits. (Huang \& Lin, 2003; Lin \& Lian, 2008) proposed a DSP-based self-organizing fuzzy controller for an active suspension system of car, to reduce the displacement and acceleration in the sprung mass so as to improve the handling performance and ride comfort of the car. (Lian et al., Feb. 2005) proposed a fuzzy controller to control the active suspension system.

However, it is still complicated to design suitable membership functions and fuzzy linguistic rules of the fuzzy logic controllers to give suitable learning rate and weighting distribution parameters in the self-organizing fuzzy controller.

Since, the aforementioned fuzzy logic and neural network controllers on active models, did not give enough information about the robustness, sensitivity and rattle space limits. These techniques were combined with wavelets to solve different control and signal processing problems and collectively known as Fuzzy Wavelet Neural Networks (FWNNs) (Chalasani, 1986; Hac, 1986; Heo et al., 2000; Meld, 1991; Thompson \& Davis, 2005; Thompson \& Pearce, 1998). The combination of a fuzzy wavelet neural inference system comprises the strength of the optimal definitions of the antecedent part and the consequent part of the fuzzy rules. In this study, fuzzy wavelet neural network control is proposed for the active suspension control. A FWNN combines wavelet theory with fuzzy logic and neural networks. Wavelet neural networks are based on wavelet transform which has the capability to examine non-stationary signals to determine their local details. Fuzzy logic system decreases the complexity and deals with vagueness of the data. Neural networks have self-learning qualities that raises the precision of the model. Their arrangement permits to build up a system with fast learning abilities that can explain nonlinear structures. Different structures of FWNN have been proposed in the literature. Due to its strong estimation and controlling properties FWNN has found extensive applications in the areas of identification and control of non-linear plants (Abiyev \& Kaynak, 2008; Adeli \& Jiang, 2006; Banakar \& Azeem, 2008; Yilmaz \& Oysal, 2010).

In this chapter, different softcomputing techniques have been combined with wavelets for the active suspension control of full car model to minimize the vibrations of the vehicle against the road disturbances. The proposed Adaptive Fuzzy Wavelet Neural Network (AFWNN) control integrates the ability of wavelet to analyze the local details of the signal with that of fuzzy logic to reduce system complexity and with the self learning capability of neural networks, which makes the controller efficient for controlling unknown dynamic plants. The results of the proposed models have been compared with passive and semi-active suspension system. The robustness of the system has further been evaluated by comparing the results with Adaptive PID (APID).

This chapter has been arranged as follows; Section2 gives the structural and mathematical details of the proposed AFWNN models. In Section 3 the modeling details and closed loop 
system have been discussed. Section 4 gives the simulation results and discussion. Finally, section 5 concludes our work.

\section{Fuzzy wavelet neural network control}

Wavelet neural network is a new and innovative network, which is based on wavelet transforms (Oussar \& Dreyfus, 2000). The structural design of the wavelet neural network is laid on a multilayered perceptron. A discrete wavelet function is applied as node activation function in the wavelet neural network. Because, the wavelet space is utilized as a feature space of pattern identification, the feature extraction of signal is recognized by the weighted sum of the inner product of wavelet base and signal vector. Furthermore, network acquires the ability of approximation and robustness. The entire estimation is on the logistic infrastructure. Wavelets can be expressed as follows:

$$
\Psi_{j}(x)=\left|a_{j}\right|^{\frac{-1}{2}} \Psi\left(\frac{x-b_{j}}{a_{j}}\right), \quad a_{j} \neq 0, \quad j=1,2, \ldots, n
$$

Where, $\Psi_{j}(x)$ is the family of wavelets, $x=x_{1}, x_{2}, \ldots, x_{m}$ shows the input values, $a_{j}=$ $a_{1 j}, a_{2 j}, \ldots, a_{m j}$ and $b_{j}=b_{1 j}, b_{2 j}, \ldots, b_{m j}$ represent the dilation and translation parameters of the mother wavelet $\Psi(x)$, respectively. The $\Psi(x)$ function is a waveform of limited duration and has a zero mean value.

Wavelet neural networks are mainly three layered networks using wavelets as activation function. The output for wavelet neural network is formulated as;

$$
y=\sum_{j=1}^{k} w_{j} \Psi_{j}(x)
$$

Where, $\Psi_{j}(x)$ is the wavelet function of the $j$ th part of hidden layer, because, the wavelet networks contain the wavelet functions in the hidden layer's neurons of the network. $w_{j}$ are the weights connected between the hidden layer and the output layer.

Wavelet functions have capability of time-frequency localization property (Zhang \& Benveniste, 1992). Localization of the ith hidden layer of wavelet neural network is found by the dilation and translation parameters of the wavelet function. The dilation parameter controls the spread of the wavelet and the translation parameter determines the center position of the wavelet (Y. Chen \& Dong, 2006).

Normally, two techniques are used for signifying multidimensional wavelets. In the first technique, they are created by using the product of one-dimensional wavelet functions. This wavelet neural network technique model is used by (Zhang et al., 1995). In second technique, the Euclidian norms of the input variables are used as the inputs of one-dimensional wavelets (Billings \& Wei, 2005; Zhang, 1997).

The proposed AFWNN incorporates wavelet functions in the conventional TSK fuzzy logic system. In the conventional approach, a linear function or constant is used in the consequent part of the linguistic rules for TSK fuzzy system. In the AFWNN, wavelet functions are used in the consequent part to enhance the estimation capability and computational strength of the neuro-fuzzy system by utilizing their time-frequency localization property. 
In a TSK fuzzy model, each rule is divided into two regions, represented by the IF-THEN statement. In the IF part of the fuzzy rule, membership functions are given, and in the THEN part of the fuzzy rule a linear function of inputs or a constant is used. These rules are based on either experts knowledge or adaptive learning. The wavelets can collect the information globally and locally easily by means of the multiresolution property (Ho et al., 2001). The proposed AFWNN model has fast convergence and accuracy properties.

The AFWNN rules have the following form;

$$
\begin{aligned}
& \text { If } x_{1} \text { is } A_{11} \text { and } x_{2} \text { is } A_{12} \text { and } \ldots x_{m} \text { is } A_{1 m} \text { Then } y_{1}=\sum_{i=1}^{m} w_{i 1}\left(1-q_{i 1}^{2}\right) e^{-\frac{q_{i 1}^{2}}{2}} \\
& \text { If } x_{1} \text { is } A_{21} \text { and } x_{2} \text { is } A_{22} \text { and } \ldots x_{m} \text { is } A_{2 m} \text { Then } y_{2}=\sum_{i=1}^{m} w_{i 2}\left(1-q_{i 2}^{2}\right) e^{-\frac{q_{i 2}^{2}}{2}} \\
& \qquad \vdots \\
& \text { If } x_{1} \text { is } A_{n 1} \text { and } x_{2} \text { is } A_{n 2} \text { and } \ldots x_{m} \text { is } A_{n m} \text { Then } y_{n}=\sum_{i=1}^{m} w_{i n}\left(1-q_{i n}^{2}\right) e^{-\frac{q_{i n}^{2}}{2}}
\end{aligned}
$$

Where, $x_{1}, x_{2}, \ldots, x_{m}, y_{1}, y_{2}, \ldots, y_{n}$ are the input-output variables and $A_{i j}$ is the membership function of $i t h$ input and $j$ th rule. Wavelet functions are in the consequent part of the rules. The entire fuzzy model can be attained by finding/learning the parameters of antecedent and consequent part.

The AFWNN structure has been depicted in Figure 1. This structure comprises of combination of the two network structures, i.e., upper side and lower side. Where, upper side encloses wavelet neural network and lower side encloses fuzzy reasoning process.

The whole network works in a layered fashion, as follows;

Layer 1: This is the first layer of fuzzy reasoning as well as the wavelet network. This layer accepts input values. Its nodes transmit input values to the next layer.

Layer 2: In this layer fuzzification process is performed and neurons represent fuzzy sets used in the antecedent part of the linguistic fuzzy rules. The outputs of this layer are the values of the membership functions ' $\eta_{j}\left(x_{j}\right)$ '.

Layer 3: In this layer each node represents a fuzzy rule. In order to compute the firing strength of each rule, and min operation is used to estimate the output value of the layer. i.e.,

$$
\mu_{j}(x)=\prod_{i} \eta_{j}\left(x_{i}\right)
$$

where, $\prod_{i}$ is the min operation and $\mu_{j}(x)$ are the input values for the next layer (consequent layer).

Layer 4: In this layer, wavelet functions are represented. The output of this layer is given by;

$$
y_{l}=w_{l} \psi_{l}(q)
$$

Where, $\psi_{l}=f\left(a_{i l}, q_{i l}\right)$ is a functional such that

$$
q_{i l}=f\left(x_{i}, b_{i l}, a_{i l}\right)
$$




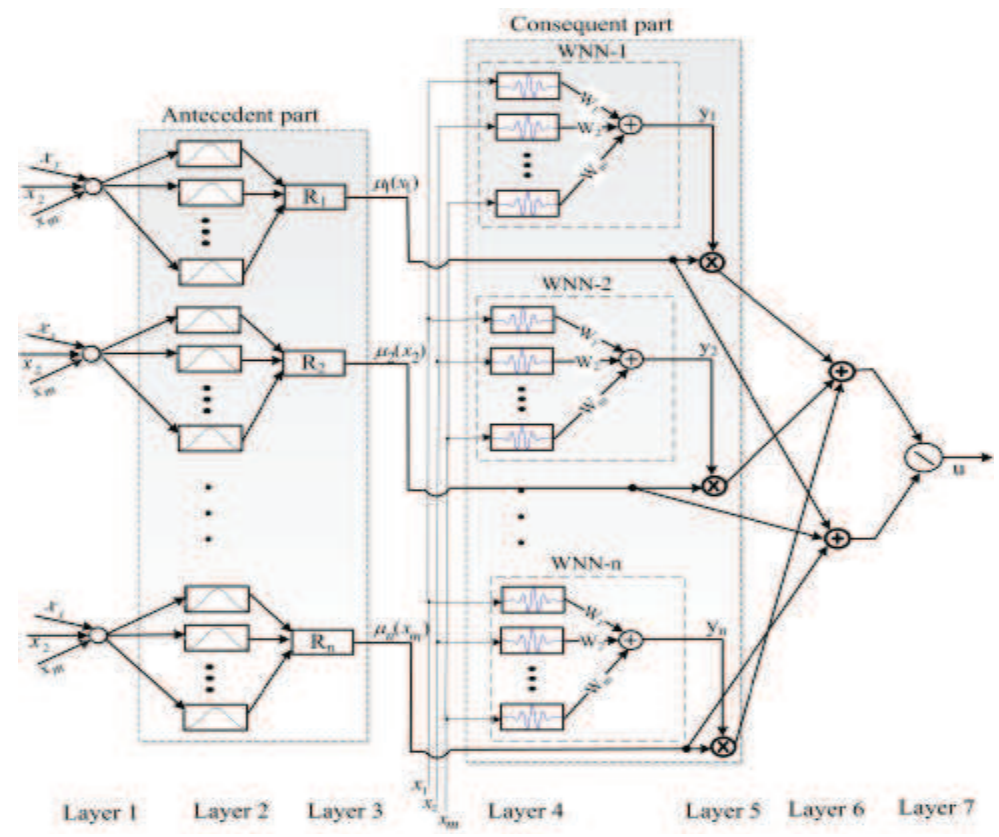

Fig. 1. Structure of AFWNN

Here, ' $b_{i l}$ ' and ' $a_{i l}$ ' represent the parameters for the ' $i t h$ ' input and ' $l t h$ ' output of the wavelet function. Where, $i=1,2, \ldots, n$ and $l=1,2, \ldots, n$.

Layer 5: This layer estimates the weighted consequent value of a given rule.

Layer 6, 7: In these layers, the defuzzification process is made to calculate the output of the entire network, i.e., it computes the overall output of system. Therefore, the output for the fuzzy wavelet neural network can be expressed as;

$$
u=\frac{\sum_{l=1}^{n} \mu_{l}(x) y_{l}}{\sum_{l=1}^{n} \mu_{l}(x)}
$$

Where, ' $u$ ' is the output for the entire network. The training of the network starts after estimating the output value of the AFWNN.

The AFWNN learning is to minimize a given function or input and output values by adjusting network parameters. Adapted parameters are mean ' $g_{i j}$ ' and variance ' $\sigma_{i j}$ ' of membership functions in antecedent part, translation ' $b_{i j}$ ' and dilation ' $a_{i j}$ ' parameters of wavelet functions and weights ' $w_{i j}$ ' are the parameters in the consequent part of the rules.

The AFWNN learning is done by minimizing the performance index. In this study, the gradient descent technique has been used to speed up the convergence and minimize the cost function. 
The performance index can be expressed as;

$$
\begin{aligned}
J & =\frac{1}{2} \sum_{i=0}^{O} e^{2} \\
& =\frac{1}{2} \sum_{i=0}^{O}\left(r_{i}-u_{i}\right)^{2}
\end{aligned}
$$

Where, ' $r_{i}$ ' and ' $u_{i}$ ' are the desired and current output values of the system, respectively. ' $O$ ' shows the number of the output values of the system, which is one in our case. The update parameters ' $w_{l}{ }^{\prime},{ }^{\prime}{ }_{i l}$ ' ' ' $b_{i l}$ ' of the consequent part of network and ' $g_{i l}$ ' and ' $\sigma_{i l}$ ' (i= $1,2, \ldots, m, j=1,2, \ldots, n)$ of the antecedent part of the network can be formulated as follows;

$$
\begin{aligned}
& w_{l}(t+1)=w_{l}(t)-\gamma \frac{\partial J}{\partial w_{l}}+\lambda\left(w_{l}(t)-w_{l}(t-1)\right) \\
& a_{i l}(t+1)=a_{i l}(t)-\gamma \frac{\partial J}{\partial a_{i l}}+\lambda\left(a_{i l}(t)-a_{i l}(t-1)\right) \\
& b_{i l}(t+1)=b_{i l}(t)-\gamma \frac{\partial J}{\partial b_{i l}}+\lambda\left(b_{i l}(t)-b_{i l}(t-1)\right) \\
& g_{i j}(t+1)=g_{i j}(t)-\gamma \frac{\partial J}{\partial g_{i j}} \\
& \sigma_{i j}(t+1)=\sigma_{i j}(t)-\gamma \frac{\partial J}{\partial \sigma_{i j}}
\end{aligned}
$$

Where, ' $\gamma$ ' and ' $\lambda$ ' represent the learning rate and momentum, respectively. ' $m$ ' and ' $n$ ' shows the input values and rules number of the network such that $i=1,2, \ldots, m$ and $j=1,2, \ldots, n$.

By using chain rule the partial derivatives shown in the above equations can be expanded as;

$$
\begin{aligned}
\frac{\partial J}{\partial w_{l}} & =\frac{\partial J}{\partial u} \frac{\partial u}{\partial y_{l}} \frac{\partial y_{l}}{\partial w_{l}} \\
\frac{\partial J}{\partial a_{i l}} & =\frac{\partial J}{\partial u} \frac{\partial u}{\partial y_{l}} \frac{\partial y_{l}}{\partial \psi_{l}} \frac{\partial \psi_{l}}{\partial q_{i l}} \frac{\partial q_{i l}}{\partial a_{i l}} \\
\frac{\partial J}{\partial b_{i l}} & =\frac{\partial J}{\partial u} \frac{\partial u}{\partial y_{l}} \frac{\partial y_{l}}{\partial \psi_{l}} \frac{\partial \psi_{l}}{\partial q_{l}} \frac{\partial q_{l}}{\partial b_{l}} \\
\frac{\partial J}{\partial g_{i j}} & =\sum_{j} \frac{\partial J}{\partial u} \frac{\partial u}{\partial \mu_{j}} \frac{\partial \mu_{j}}{\partial g_{i j}} \\
\frac{\partial J}{\partial \sigma_{i j}} & =\sum_{j} \frac{\partial J}{\partial u} \frac{\partial u}{\partial \mu_{j}} \frac{\partial \mu_{j}}{\partial \sigma_{i j}}
\end{aligned}
$$

Equations (12) to (16) shows the contribution of update parameters for change in error. The following sections give a brief detail of different configurations of AFWNN, applied to full car model. Since, the full car active suspension control is a nonlinear problem, the idea is to check different combinations of wavelets and membership functions to increase the nonlinearity of the controller as well so that it could efficiently deal with a nonlinear system. 


\subsection{AFWNN-1: Structure and parameters update rules for learning}

AFWNN-1 structure uses Gaussian membership function in the antecedent part and Mexican hat wavelet in the consequent part. The gaussian membership function is given by;

$$
\eta_{j}\left(x_{i}\right)=e^{-\left(x_{i}-g_{i j}\right)^{2} / \sigma_{i j}^{2}} \quad i=1,2, \ldots, m, \quad j=1,2, \ldots, n
$$

Where, ' $\eta_{j}\left(x_{j}\right)$ ' shows the membership function, ' $g_{i j}$ ' and ' $\sigma_{i j}$ ' are the mean and variance of membership function of the jith term of $i t h$ input variable. ' $m$ ' and ' $n$ ' are the number of input signals and number of nodes in second layer, respectively.

The Mexican hat wavelet function is given by;

$$
\psi\left(q_{i}\right)=\sum_{i=1}^{m}\left|a_{i}\right|^{-1 / 2}\left(1-q_{i}^{2}\right) e^{-q_{i}^{2} / 2}
$$

where,

$$
q_{j}=\frac{x-b_{j}}{a_{j}}
$$

Where, $\Psi_{j}(x)$ is the family of wavelets, $x=x_{1}, x_{2}, \ldots, x_{m}$ shows the inputs values, $a_{j}=$ $a_{1 j}, a_{2 j}, \ldots, a_{m j}$ and $b_{j}=b_{1 j}, b_{2 j}, \ldots, b_{m j}$ represent the dilation and translation parameters of the mother wavelet $\Psi(x)$, respectively. Figure 2(a) shows Mexican wavelet function.

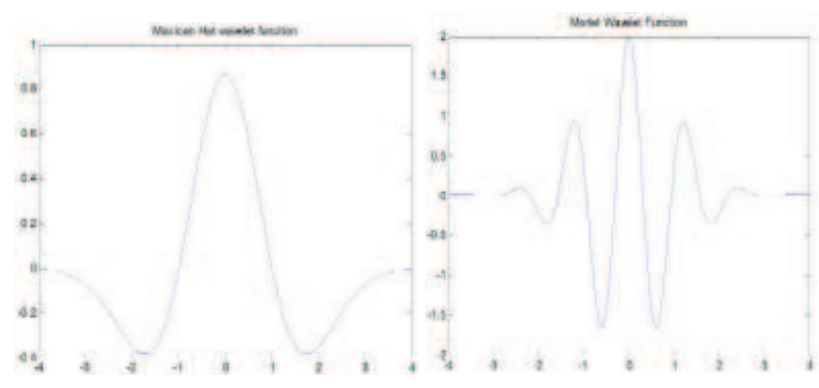
(a) Mexican hat
(b) Morlet

Fig. 2. Wavelet functions

Referring to equations (12) to (16) and simplifying gives the following results;

$$
\begin{aligned}
\frac{\partial J}{\partial w_{l}} & =(u(t)-r(t)) \mu_{l}(x) \cdot \psi\left(q_{l}\right) / \sum_{l=1}^{n} \mu_{l}(x) \\
\frac{\partial J}{\partial a_{i l}} & =\delta_{i} \frac{\left(-3.5 q_{i l}^{2}-q_{i l}^{4}-0.5\right) e^{-q_{i l}^{2} / 2}}{\sqrt{a_{i l}^{3}}} \\
\frac{\partial J}{\partial b_{i l}} & =\delta_{l}\left(3 q_{i l}-q_{i l}^{3}\right) e^{-q_{i l}^{2} / 2} /\left(\sqrt{a_{i l}^{3}}\right)
\end{aligned}
$$




$$
\begin{aligned}
\frac{\partial J}{\partial g_{i j}} & =\sum_{j}(u(t)-r(t)) \frac{y_{j}-u}{\sum_{j} \mu_{j}} \mu_{j}\left(x_{i}\right) \frac{2\left(x_{i}-g_{i j}\right)}{\sigma_{i j}^{2}} \\
\frac{\partial J}{\partial \sigma_{i j}} & =\sum_{j}(u(t)-r(t)) \cdot \frac{y_{j}-u}{\sum_{j} \mu_{j}(x)} \cdot u_{j}\left(x_{i}\right) \frac{2\left(x_{i}-g_{i j}\right)^{2}}{\sigma_{i j}^{3}}
\end{aligned}
$$

where,

$$
\delta_{l}=(u(t)-r(t)) \mu_{l}(x) \cdot w_{l} / \sum_{l=1}^{n} \mu_{l}(x)
$$

Putting these values in respective equations from equation (7) to equation (11), gives the final update equations for AFWNN-1 as follows;

$$
\begin{aligned}
w_{l}(t+1) & =w_{l}(t)-\gamma(u(t)-r(t)) \mu_{l}(x) \cdot \psi_{l}(q) / \sum_{l=1}^{n} \mu_{l}(x)+\lambda\left(w_{l}(t)-w_{l}(t-1)\right) \\
a_{i l}(t+1) & =a_{i l}(t)-\gamma \delta_{l} \frac{\left(3.5 q_{i l}^{2}-q_{i l}^{4}-0.5\right) e^{-q_{i l}^{2} / 2}}{\sqrt{a_{i l}^{3}}}+\lambda\left(a_{i l}(t)-a_{i l}(t-1)\right) \\
\Rightarrow a_{i l}(t+1) & =a_{i l}(t)-\frac{\gamma(u(t)-r(t)) \mu_{l}(x) \cdot w_{l}(q)}{\sum_{l=1}^{n} \mu_{l}(x)} \frac{\left(3.5 q_{i l}^{2}-q_{i l}^{4}-0.5\right) e^{-q_{i l}^{2} / 2}}{\sqrt{a_{i l}^{3}}} \\
& +\lambda\left(a_{i l}(t)-a_{i l}(t-1)\right) \\
b_{i l}(t+1) & =b_{i l}(t)-\gamma \delta_{l}\left[\left|a_{i l}\right|^{-1 / 2}\left(-3 q_{i l}+q_{i l}^{3}\right) e^{-q_{i l}^{2} / 2}\left(\frac{-1}{a_{i l}}\right)\right] \\
& +\lambda\left(b_{i l}(t)-b_{i l}(t-1)\right) \\
b_{i l}(t+1) & =b_{i l}(t)-\frac{\gamma(u(t)-r(t)) \mu_{l}(x) \cdot w_{l}(q)}{\sum_{l=1}^{n} \mu_{l}(x)}\left[\left|a_{i l}\right|^{-1 / 2}\left(-3 q_{i l}+q_{i l}^{3}\right) e^{-q_{i l}^{2} / 2}\left(\frac{-1}{a_{i l}}\right)\right] \\
& +\lambda\left(b_{i l}(t)-b_{i l}(t-1)\right) \\
\sigma_{i j}(t+1) & =\sigma_{i j}(t)-\sum_{j}(u(t)-r(t)) \cdot \frac{y_{j}-u}{\sum_{j} \mu_{j}(x)} \cdot u_{j}\left(x_{i}\right) \frac{2\left(x_{i}-g_{i j}\right)^{2}}{\sigma_{i j}^{3}} \\
g_{i j}(t+1) & =g_{i j}(t)-\sum_{j}(u(t)-r(t)) \frac{y_{j}-u}{\sum_{j} \mu_{j}} \mu_{j}\left(x_{i}\right) \frac{2\left(x_{i}-g_{i j}\right)}{\sigma_{i j}^{2}}
\end{aligned}
$$

The gradient descent method shows convergence on the basis of the learning rate and the momentum value. The values of the learning rate and momentum are usually taken in interval $[0,1]$. If the value of the learning rate is high, it makes the system unstable and if its value is small the convergence process is slow. The momentum term ' $\lambda$ ' speeds up the learning process. 


\subsection{AFWNN-2: Structure and parameters update rules for learning}

In AFWNN-2, linear function or constant in the consequent part of the linguistic rules in TSK fuzzy system are replaced with Mexican hat wavelet function. The Mexican Hat wavelet function is given by equation (18), as for AFWNN-1. To illustrate the linguistic term, the Triangular membership function has been used for this neuro-fuzzy system and is given by,

$$
\eta_{j}\left(x_{i}\right)=1-\frac{2\left|x_{i}-g_{i j}\right|}{\sigma_{i j}} \quad i=1,2, \ldots, m, \quad j=1,2, \ldots, n
$$

Where, ' $\eta_{j}\left(x_{j}\right)$ ' shows the membership function, ' $g_{i j}$ ' and ' $\sigma_{i j}$ ' are the mean and variance of membership function of the ' $j i t h$ ' term of ' $i t h$ ' input variable. In order to calculate the updated values for this network simplifying the Equations (12) to (16) give the following results;

$$
\begin{aligned}
\frac{\partial J}{\partial w_{l}} & =(u(t)-r(t)) \mu_{l}(x) \cdot \psi\left(q_{l}\right) / \sum_{l=1}^{n} \mu_{l}(x) \\
\frac{\partial J}{\partial a_{i l}} & =\delta_{l} \frac{\left(-3.5 q_{i l}^{2}-q_{i l}^{4}-0.5\right) e^{-q_{i l}^{2} / 2}}{\sqrt{a_{i l}^{3}}} \\
\frac{\partial J}{\partial b_{i l}} & =\delta_{l}\left(3 q_{i l}-q_{i l}^{3}\right) e^{-q_{i l}^{2} / 2} /\left(\sqrt{a_{i l}^{3}}\right) \\
\frac{\partial J}{\partial g_{i j}} & =\sum_{j}\left[(u(t)-r(t)) \cdot \frac{y_{j}-u}{\sum_{j} \mu_{j}} \frac{\mu_{j}}{\eta_{j}\left(x_{i}\right)} \cdot \frac{\operatorname{sign}\left(x_{i}-g_{i j}\right)}{\sigma_{i j}}\right] \\
\frac{\partial J}{\partial \sigma_{i j}} & =\sum_{j}\left[(u(t)-r(t) \cdot) \frac{y_{j}-u}{\sum_{j} \mu_{j}} \cdot \frac{\mu_{j}}{\eta_{j}\left(x_{i}\right)} \frac{1-\eta_{j}}{\sigma_{i j}}\right]
\end{aligned}
$$

By putting these values in Equations (7) to (11) the final update equations are given by;

$$
\begin{aligned}
w_{l}(t+1) & =w_{l}(t)-\gamma(u(t)-r(t)) \mu_{l}(x) \cdot \psi_{l}(q) / \sum_{l=1}^{n} \mu_{l}(x) \\
& +\lambda\left(w_{l}(t)-w_{l}(t-1)\right) \\
a_{i l}(t+1) & =a_{i l}(t)-\gamma \delta_{l} \frac{\left(-3.5 q_{i l}^{2}-q_{i l}^{4}-0.5\right) e^{-q_{i l}^{2} / 2}}{\sqrt{a_{i l}^{3}}} \\
& +\lambda\left(a_{i l}(t)-a_{i l}(t-1)\right) \\
\Rightarrow a_{i l}(t+1) & =a_{i l}(t)-\frac{\gamma(u(t)-r(t)) \mu_{l}(x) \cdot w_{l}(q)}{\sum_{l=1}^{n} \mu_{l}(x)} \frac{\left(-3.5 q_{i l}^{2}-q_{i l}^{4}-0.5\right) e^{-q_{i l}^{2} / 2}}{\sqrt{a_{i l}^{3}}} \\
& +\lambda\left(a_{i l}(t)-a_{i l}(t-1)\right) \\
b_{i l}(t+1) & =b_{i l}(t)-\gamma \delta_{l}\left[\left|a_{i l}\right|-1 / 2\left(-3 q_{i l}+q_{i l}^{3}\right) e^{-q_{i l}^{2} / 2}\left(\frac{-1}{a_{i l}}\right)\right] \\
& +\lambda\left(b_{i l}(t)-b_{i l}(t-1)\right)
\end{aligned}
$$




$$
\begin{aligned}
\Rightarrow b_{i l}(t+1) & =b_{i l}(t)-\frac{\gamma(u(t)-r(t)) \mu_{l}(x) \cdot w_{l}(q)}{\sum_{l=1}^{n} \mu_{l}(x)}\left[\left|a_{i l}\right|^{-1 / 2}\left(-3 q_{i l}+q_{i l}^{3}\right) e^{-q_{i l}^{2} / 2}\left(\frac{-1}{a_{i l}}\right)\right] \\
& +\lambda\left(b_{i l}(t)-b_{i l}(t-1)\right) \\
g_{i j}(t+1) & =g_{i j}(t)-\gamma \sum_{j}\left[(u(t)-r(t)) \cdot \frac{y_{j}-u}{\sum_{j} \mu_{j}} \frac{\mu_{j}}{\eta_{j}\left(x_{i}\right)} \cdot 2 \frac{\operatorname{sign}\left(x_{i}-g_{i j}\right)}{\sigma_{i j}}\right] \\
\sigma_{i j}(t+1) & =\sigma_{i j}(t)-\gamma \sum_{j}\left[(u(t)-r(t) \cdot) \frac{y_{j}-u}{\sum_{j} \mu_{j}} \cdot \frac{\mu_{j}}{\eta_{j}\left(x_{i}\right)} \frac{1-\eta_{j}}{\sigma_{i j}}\right]
\end{aligned}
$$

Hence, these are the required equations for the update parameters, ' $w_{l}{ }^{\prime}, ' a_{i l}{ }^{\prime}$, ' $b_{i l}{ }^{\prime}$, ' $g_{i l}$ ' and ' $\sigma_{i l}$ ' respectively.

\subsection{AFWNN-3: Structure and parameters update rules for learning}

In AFWNN-3 the consequent part uses Morlet wavelet function whereas the antecedent part uses the same Gaussian membership function as that of AFWNN-1. The Morlet wavelet function has been shown in Figure 2(b) and is given by;

$$
\Psi_{j}(x)=\cos \left(5 q_{j}\right) e^{-\frac{1}{2}\left(q_{j}^{2}\right)}
$$

The Gaussian membership function is given by equation (17); The output value ' $y$ ' for the ' $l t h$ ' wavelet network is given by;

$$
\begin{array}{r}
y_{l}=w_{l} \psi_{l}(q), \quad \psi_{l}(q)=\sum_{i=1}^{m} \cos \left(5 q_{i l}\right) e^{-\frac{1}{2}\left(q_{i l}^{2}\right)} \\
\Rightarrow y_{l}=w_{l} \sum_{i=1}^{m} \cos \left(5 q_{i l}\right) e^{-\frac{1}{2}\left(q_{i l}^{2}\right)} \\
\Rightarrow y_{l}=w_{l} \sum_{i=1}^{m} \cos 5\left(\frac{x_{i}-b_{i l}}{a_{i l}}\right) e^{-\frac{1}{2}\left(\frac{x_{i}-b_{i l}}{a_{i l}}\right)^{2}}
\end{array}
$$

By using equations (12) to (16), the partial derivatives can be solved as follows;

$$
\begin{aligned}
\frac{\partial J}{\partial w_{l}} & =(u(t)-r(t)) \mu_{l}(x) \cdot \psi\left(q_{l}\right) / \sum_{l=1}^{n} \mu_{l}(x) \\
\frac{\partial J}{\partial a_{i l}} & =\delta_{l}\left(\frac{\cos \left(5 q_{i l}\right) e^{-\frac{1}{2}\left(q_{i l}^{2}\right)} q_{i l}^{2}+5 q_{i l} \sin \left(5 q_{i l}\right) e^{-\frac{1}{2}\left(q_{i l}^{2}\right)}}{a_{i l}}\right) \\
\frac{\partial J}{\partial b_{i l}} & =\delta_{l}\left(\frac{\cos \left(5 q_{i l}\right) e^{-\frac{1}{2}\left(q_{i l}^{2}\right)} q_{i l}+5 \sin \left(5 q_{i l}\right) e^{-\frac{1}{2}\left(q_{i l}^{2}\right)}}{a_{i l}}\right) \\
\frac{\partial J}{\partial g_{i j}} & =\sum_{j}\left[(u(t)-r(t)) \frac{y_{j}-u}{\sum_{j} \mu_{j}} \mu_{j}\left(x_{i}\right) \frac{2\left(x_{i}-g_{i j}\right)}{\sigma_{i j}^{2}}\right] \\
\frac{\partial J}{\partial \sigma_{i j}} & =\sum_{j}\left[(u(t)-r(t)) \cdot \frac{y_{j}-u}{\sum_{j} \mu_{j}(x)} \cdot u_{j}\left(x_{i}\right) \frac{2\left(x_{i}-g_{i j}\right)^{2}}{\sigma_{i j}^{3}}\right]
\end{aligned}
$$


Equations (42) to (46) give the required values of $\frac{\partial J}{\partial w_{l}}, \frac{\partial J}{\partial a_{i l}}, \frac{\partial J}{\partial b_{i l}}, \frac{\partial J}{\partial g_{i j}}$ and $\frac{\partial J}{\partial \sigma_{i j}}$, showing the contribution of each update parameter for error convergence.

The required updates can be calculated using equations (7) to (11) as follows;

$$
\begin{aligned}
w_{l}(t+1) & =w_{l}(t)-\gamma(u(t)-r(t)) \mu_{l}(x) \cdot \psi_{l}(q) / \sum_{l=1}^{n} \mu_{l}(x)+\lambda\left(w_{l}(t)-w_{l}(t-1)\right) \\
a_{i l}(t+1) & =a_{i l}(t)-\gamma \delta_{l}\left(\frac{\cos \left(5 q_{i l}\right) e^{-\frac{1}{2}\left(q_{i l}^{2}\right)} q_{i l}^{2}+5 q_{i l} \sin \left(5 q_{i l}\right) e^{-\frac{1}{2}\left(q_{i l}^{2}\right)}}{a_{i l}}\right) \\
& +\lambda\left(a_{i l}(t)-a_{i l}(t-1)\right) \\
\Rightarrow a_{i l}(t+1) & =a_{i l}(t)-\frac{\gamma(u(t)-r(t)) \mu_{l}(x) \cdot w_{l}(q)}{\sum_{l=1}^{n} \mu_{l}(x)}\left(\frac{\cos \left(5 q_{i l}\right) e^{-\frac{1}{2}\left(q_{i l}^{2}\right)} q_{i l}^{2}+5 q_{i l} \sin \left(5 q_{i l}\right) e^{-\frac{1}{2}\left(q_{i l}^{2}\right)}}{a_{i l}}\right) \\
& +\lambda\left(a_{i l}(t)-a_{i l}(t-1)\right) \\
b_{i l}(t+1) & =b_{i l}(t)-\gamma \delta_{l}\left(\frac{\cos \left(5 q_{i l}\right) e^{-\frac{1}{2}\left(q_{i l}^{2}\right)} q_{i l}+5 \sin \left(5 q_{i l}\right) e^{-\frac{1}{2}\left(q_{i l}^{2}\right)}}{a_{i l}}\right) \\
& +\lambda\left(b_{i l}(t)-b_{i l}(t-1)\right) \\
\Rightarrow b_{i l}(t+1) & =b_{i l}(t)-\frac{\gamma(u(t)-r(t)) \mu_{l}(x) \cdot w_{l}(q)}{\sum_{l=1}^{n} \mu_{l}(x)}\left(\frac{\cos \left(5 q_{i l}\right) e^{-\frac{1}{2}\left(q_{i l}^{2}\right)} q_{i l}+5 \sin \left(5 q_{i l}\right) e^{-\frac{1}{2}\left(q_{i l}^{2}\right)}}{a_{i l}}\right) \\
& +\lambda\left(b_{i l}(t)-b_{i l}(t-1)\right) \\
\sigma_{i j}(t+1) & =\sigma_{i j}(t)-\gamma \sum_{j} u(t)-r(t) \frac{y_{j}-u}{\sum_{j} \mu_{j}} \mu_{j}\left(x_{i}\right) \frac{2\left(x_{i}-g_{i j}\right)^{2}}{\sigma_{i j}^{3}} \\
g_{i j}(t+1) & =g_{i j}(t)-\gamma \sum_{j} u(t)-r(t) \frac{y_{j}-u}{\sum_{j} \mu_{j}} \mu_{j}\left(x_{i}\right) \frac{2\left(x_{i}-g_{i j}\right)}{\sigma_{i j}^{2}}
\end{aligned}
$$

Hence, these are the required equations for the update parameters $w_{l}, a_{i l}, b_{i l}, g_{i l}$ and $\sigma_{i l}$.

\subsection{AFWNN-4: Structure and parameters update rules for learning}

AFWNN-4 uses Morlet wavelet function along with triangular membership function. The triangular membership function is given by Equation (29). Using Morlet wavelet function the output value ' $y$ ' for the ' $l t h$ ' wavelet is given by;

$$
\begin{aligned}
y_{l} & =w_{l} \psi_{l}(q), \quad \psi_{l}(q)=\sum_{i=1}^{m} \cos \left(5 q_{i l}\right) e^{-\frac{1}{2}\left(q_{i l}^{2}\right)} \\
\Rightarrow y_{l} & =w_{l} \sum_{i=1}^{m} \cos 5\left(\frac{x_{i}-b_{i l}}{a_{i l}}\right) e^{-\frac{1}{2}\left(\frac{x_{i}-b_{i l}}{a_{i l}}\right)^{2}}
\end{aligned}
$$


The derivatives given by equations (12) to (16) can be simplified as follows;

$$
\begin{aligned}
\frac{\partial J}{\partial w_{l}} & =(u(t)-r(t)) \mu_{l}(x) \cdot \psi\left(q_{l}\right) / \sum_{l=1}^{n} \mu_{l}(x) \\
\frac{\partial J}{\partial a_{i l}} & =\delta_{l}\left(\frac{\cos \left(5 q_{i l}\right) e^{-\frac{1}{2}\left(q_{i l}^{2}\right)} q_{i l}^{2}+5 q_{i l} \sin \left(5 q_{i l}\right) e^{-\frac{1}{2}\left(q_{i l}^{2}\right)}}{a_{i l}}\right) \\
\frac{\partial J}{\partial b_{i l}} & =\delta_{l}\left(\frac{\cos \left(5 q_{i l}\right) e^{-\frac{1}{2}\left(q_{i l}^{2}\right)} q_{i l}+5 \sin \left(5 q_{i l}\right) e^{-\frac{1}{2}\left(q_{i l}^{2}\right)}}{a_{i l}}\right) \\
\frac{\partial J}{\partial g_{i j}} & =\sum_{j}\left[(u(t)-r(t)) \cdot \frac{y_{j}-u}{\sum_{j} \mu_{j}} \frac{\mu_{j}}{\eta_{j}\left(x_{i}\right)} \cdot 2 \frac{\operatorname{sign}\left(x_{i}-g_{i j}\right)}{\sigma_{i j}}\right] \\
\frac{\partial J}{\partial \sigma_{i j}} & =\sum_{j}\left[(u(t)-r(t)) \frac{y_{j}-u}{\sum_{j} \mu_{j}} \cdot \frac{\mu_{j}}{\eta_{j}\left(x_{i}\right)} \frac{1-\eta_{j}}{\sigma_{i j}}\right]
\end{aligned}
$$

Equations (53) to (57) give the required values of $\frac{\partial J}{\partial w_{l}}, \frac{\partial J}{\partial a_{i l}}, \frac{\partial J}{\partial b_{i l}}, \frac{\partial J}{\partial g_{i j}}$ and $\frac{\partial J}{\partial \sigma_{i j}}$, respectively.

Using Equations (7) to (11) the updates can be found as follows;

$$
\begin{aligned}
w_{l}(t+1) & =w_{l}(t)-\gamma(u(t)-r(t)) \mu_{l}(x) \cdot \psi_{l}(q) / \sum_{l=1}^{n} \mu_{l}(x) \\
& +\lambda\left(w_{l}(t)-w_{l}(t-1)\right) \\
a_{i l}(t+1) & =a_{i l}(t)-\gamma \delta_{l}\left(\frac{\cos \left(5 q_{i l}\right) e^{-\frac{1}{2}\left(q_{i l}^{2}\right)} q_{i l}^{2}+5 q_{i l} \sin \left(5 q_{i l}\right) e^{-\frac{1}{2}\left(q_{i l}^{2}\right)}}{a_{i l}}\right) \\
& +\lambda\left(a_{i l}(t)-a_{i l}(t-1)\right) \\
\Rightarrow a_{i l}(t+1) & =a_{i l}(t)-\frac{\gamma(u(t)-r(t)) \mu_{l}(x) \cdot w_{l}(q)}{\sum_{l=1}^{n} \mu_{l}(x)}\left(\frac{\cos \left(5 q_{i l}\right) e^{-\frac{1}{2}\left(q_{i l}^{2}\right)} q_{i l}^{2}+5 q_{i l} \sin \left(5 q_{i l}\right) e^{-\frac{1}{2}\left(q_{i l}^{2}\right)}}{a_{i l}}\right) \\
& +\lambda\left(a_{i l}(t)-a_{i l}(t-1)\right) \\
& +\lambda\left(b_{i l}(t)-b_{i l}(t-1)\right) \\
b_{i l}(t+1) & =b_{i l}(t)-\gamma \delta_{l}\left(\frac{\cos \left(5 q_{i l}\right) e^{-\frac{1}{2}\left(q_{i l}^{2}\right)} q_{i l}+5 \sin \left(5 q_{i l}\right) e^{-\frac{1}{2}\left(q_{i l}^{2}\right)}}{a_{i l}}\right) \\
\Rightarrow b_{i l}(t+1) & =b_{i l}(t)-\frac{\gamma(u(t)-r(t)) \mu_{l}(x) \cdot w_{l}(q)}{\sum_{l=1}^{n} \mu_{l}(x)}\left(\frac{\cos \left(5 q_{i l}\right) e^{-\frac{1}{2}\left(q_{i l}^{2}\right)} q_{i l}+5 \sin \left(5 q_{i l}\right) e^{-\frac{1}{2}\left(q_{i l}^{2}\right)}}{a_{i l}}\right) \\
& +\lambda\left(b_{i l}(t)-b_{i l}(t-1)\right) \\
g_{i j}(t+1) & =g_{i j}(t)-\gamma \sum_{j}\left[(u(t)-r(t)) \cdot \frac{y_{j}-u}{\sum_{j} \mu_{j}} \frac{\mu_{j}}{\eta_{j}\left(x_{i}\right)} \cdot 2 \frac{\operatorname{sign}\left(x_{i}-g_{i j}\right)}{\sigma_{i j}}\right] \\
\sigma_{i j}(t+1) & =\sigma_{i j}(t)-\gamma \sum_{j}\left[\left(u(t)-r(t) \cdot \frac{y_{j}-u}{\sum_{j} \mu_{j}} \cdot \frac{\mu_{j}}{\eta_{j}\left(x_{i}\right)} \frac{1-\eta_{j}}{\sigma_{i j}}\right]\right.
\end{aligned}
$$


The above equations give the parameters updates for AFWNN-4.

\section{System modeling and design}

The proposed AFWNN structures have been applied to full car model with eight degree of freedom, being closer to reality, as shown in Figure 3. The eight degrees of freedom are the four wheels displacement $\left(Z_{f, r}, Z_{f, l}, Z_{r, r}, Z_{r, l}\right)$, seat displacement ' $Z_{s}$ ', heave displacement ' $Z$ ', pitch displacement ' $\theta$ ' and roll displacement ' $\phi$ '. The car model comprises of only one sprung mass attached to the four unsprung masses at each corner. The sprung mass is allowed to have pitch, heave and roll and the unsprung masses are allowed to have heave only. For simplicity, all other motions are ignored for this model. The suspensions between the sprung mass and

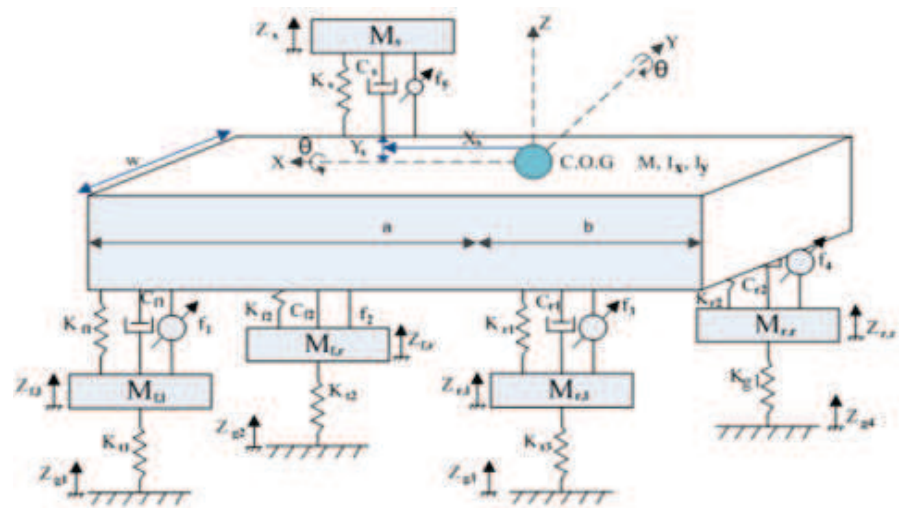

Fig. 3. Full-Car Model

unsprung masses are modeled as non-linear viscous dampers and spring components and the tires are modeled as simple non-linear springs without damping elements. The actuator gives forces that determine by the displacement of the actuator between the sprung mass and the wheels. The dampers between the wheels and car body signify sources of conventional damping like friction among the mechanical components. The inputs of full-car model are four disturbances coming through the tires and the four outputs are the heave, pitch, seat, and roll displacement. For details of the dynamic model the reader is referred to (Rahmi, 2003). Figure 4 depicts the closed loop diagram of the feedback system. The input to the plant is the noisy output of controller. The controller parameters are adapted on the basis of calculated error which is the difference between the desired and actual output of the plant.

The inputs of the plant (full-car model) are four disturbances from the tire. The outputs are Seat, Heave, Pitch and Roll displacements. The states required for controller come from displacement sensors which measure the displacement states of four tires and one more sensor for measuring the displacement of seat. The adaptive control law uses control technique and adaptation mechanism to adapt the controller itself using proposed algorithms. The general class of nonlinear MIMO systems is described by;

$$
y^{(r)}=A(x)+\sum_{i=1}^{p} \sum_{j=1}^{s} B_{i j}(x) u_{j}+\sum_{i=1}^{p} \sum_{j=1}^{s} G_{i j}(x) z_{j}
$$

Where, $x=\left[y_{1}, \dot{y}_{1}, \cdots, y_{1}^{\left(r_{1}-1\right)}, \cdots, y_{p}, \dot{y}_{p}, \cdots, y_{p}^{\left(r_{p}-1\right)}\right]^{T} \in R^{r}$ is the overall state vector, which 


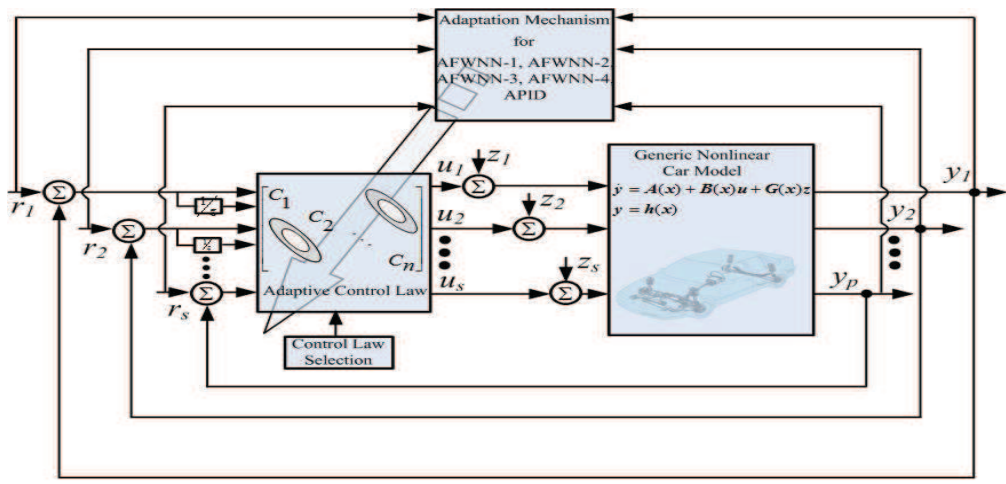

Fig. 4. Overall control system design

is assumed available and $r=r_{1}+r_{2}+\cdots+r_{p}$.

$u=\left[u_{1}, u_{2}, \cdots, u_{s}\right]^{T} \in R^{s}$ is the control input vector, $y=\left[y_{1}, \cdots, y_{p}\right]^{T} \in R^{p}$ is the output vector and $z=\left[z_{1}, \cdots, z_{s}\right]^{T} \in R^{s}$ is the disturbance vector. $A_{i}(x), i=1, \cdots, p$ are continuous non-linear functions, $B_{i j}(x), i=1, \cdots, p ; j=1, \cdots, s$ are continuous non-linear control functions and $G_{i j}(x), i=1, \cdots, p ; j=1, \cdots, s$ are continuous non-linear disturbance functions.

Let us refer;

$$
A=\left[A_{1}(x) A_{2}(x) \cdots A_{p}(x)\right]^{T}
$$

The control matrix is:

$$
B(x)=\left[\begin{array}{ccc}
b_{11}(x) & \ldots & b_{1 s}(x) \\
\vdots & \ddots & \vdots \\
b_{p 1}(x) & \ldots & b_{p s}(x)
\end{array}\right]_{p \times s}
$$

The disturbance matrix is:

$$
\begin{gathered}
G(x)=\left[\begin{array}{ccc}
g_{11}(x) & \ldots & g_{1 s}(x) \\
\vdots & \ddots & \vdots \\
g_{p 1}(x) & \ldots & g_{p s}(x)
\end{array}\right]_{p \times s} \\
y^{(r)}=\left[y_{1}^{\left(r_{1}\right)}, y_{2}^{\left(r_{2}\right)}, \ldots, y_{p}^{\left(r_{p}\right)}\right]^{T} \\
y^{(r)}=A(x)+B(x) \cdot u+G(x) . z \\
A(.) \epsilon R^{p \times p} ; \quad B(.) \epsilon R^{p \times s} ; \quad G(.) \epsilon R^{p \times s}
\end{gathered}
$$

The generic non-linear car model is,

$$
\dot{y}=f(x)+B(x) \cdot u+G(x) \cdot z
$$




$$
y=h(x)
$$

Where, $f(x) \in R^{(16 \times 16)}, B(x) \in R^{(16 \times 4)}, G(x) \in R^{(16 \times 4)}$, state vector $x \in R^{(16 \times 1)}, u \in R^{(4 \times 1)}$ and $z \in R^{(4 \times 1)}$.

These matrices can be shown in state-space form, with state vector $x$, represented in row matrix form.

$$
\begin{aligned}
f(x) & =\left[\begin{array}{llllll}
A_{1}(x) & A_{2}(x) & A_{3}(x) & \ldots & A_{16}(x)
\end{array}\right] \\
x & =\left[\begin{array}{lllll}
x_{1} & x_{2} & x_{3} & \ldots & x_{16}
\end{array}\right]^{T}
\end{aligned}
$$

$A_{1}(x)$ to $A_{8}(x)$ are velocity states and $A_{9}(x)$ to $A_{16}(x)$ are acceleration states of four tires, seat, heave, pitch and roll.

The disturbance inputs for each tire individually are represented in the form of $z$ matrix.

$$
z=\left[\begin{array}{llll}
z_{1} & z_{2} & z_{3} & z_{4}
\end{array}\right]^{T}
$$

$z_{n}$ are $n$ disturbances applied to full-car model. $u_{n}$ are $n$ control inputs to full-car model, so to regulate the car model disturbances. $y_{n}$ are $n$ states of car. $r_{n}$ are $n$ desired outputs for the controller to achieve.

Each controller in this work has two inputs. One of the inputs is ' $r_{n}$ ' and delay of it is given to second input. The $y_{n}$ states are fed to the controller as an error, so to adapt the update adaptation law for the desired regulation. Based on this error the adaptation law is formulated using AFWNN-1, AFWNN-2, AFWNN-3 and AFWNN-4. The algorithms develop a back-propagation algorithm for training the controller to achieve the desire performance.

In this work for the full-car model four states of tires are used by the four controllers as an error to adapt the adaptation law. As the purpose of controller is to regulate the disturbances so $r_{n}{ }^{\prime}$ s are zero, the second input of controllers is a delayed version of first input. The adaptation law of the controller provides the control inputs $u_{1}, u_{2}, u_{3}$ and $u_{4}$ to plant so as to regulate the plant. The four disturbances $z_{1}, z_{2}, z_{3}$ and $z_{4}$ are coming from road through tires into suspension system and to the body of the vehicle.

Two cases have been considered. In the first case, only the states of the four tires $y_{1}, y_{2}, y_{3}$ and $y_{4}$ displacement are used as an error to the controller. Which develops the control law according to that error. These control inputs $u_{1}, u_{2}, u_{3}$ and $u_{4}$ are provided to the plant from each controller (placed on each tire) to achieve the desired performance of the plant (full-car model) i.e. both better passenger comfort (better seat and heave displacement) and better vehicle stability (better heave, pitch and roll displacement). In the second case, an additional controller is applied under the driver seat to improve the passenger comfort. In this case, another state $y_{5}$ is used as an error input to the controller. This additional control input will help in reducing the disturbance effect and improving the passenger comfort.

Table 1 gives the description of different constants and their respective values used for simulation.

\section{Simulation results and discussion}

Four different types of fuzzy wavelet neural network control techniques in addition to the APID and semi-active control have been applied to full car suspension model. AFWNNC-1 


\begin{tabular}{|c|l|c|c|}
\hline \hline Constants & Description & Values & Units \\
\hline \hline$k_{f 1}, k_{f 2}$ & Front-left and Front-right suspension stuffiness, respectively. & 15000 & $\mathrm{~N} / \mathrm{m}$ \\
\hline$k_{r 1}, k_{r 2}$ & Rear-left and rear-right suspension stuffiness, respectively. & 17000 & $\mathrm{~N} / \mathrm{m}$ \\
\hline$k_{s}$ & Seat spring Constant & 15000 & $\mathrm{~N} / \mathrm{m}$ \\
\hline$c_{s}$ & Seat damping Constant & 15000 & $\mathrm{~N} / \mathrm{m}$ \\
\hline & Front-left, Front-right, rear-right and rear-left tire damping, & & \\
$c_{s 1}-c_{s 4}$ & respectively. & 2500 & $\mathrm{~N} . \mathrm{sec} / \mathrm{m}$ \\
\hline$k_{t 1}-k_{t 4}$ & $\begin{array}{l}\text { Front-left, Front-right, rear-right and rear-left tire suspension, } \\
\text { respectively. }\end{array}$ & 250000 & $\mathrm{~N} / \mathrm{m}$ \\
\hline$a$ & Distance between front axle suspension and C.O.G. & 1.2 & $\mathrm{~m}$ \\
\hline$b$ & Distance between rear axle suspension and C.O.G. & 1.4 & $\mathrm{~m}$ \\
\hline$X_{s}$ & Horizontal distance of seat from C.O.G. & 0.3 & $\mathrm{~m}$ \\
\hline$Y_{s}$ & Vertical distance of seat from C.O.G. & 0.25 & $\mathrm{~m}$ \\
\hline$M_{f, l}, M_{f, r}$ & Front-left and Front-right unsprung mass, respectively. & 25 & $\mathrm{~kg}$ \\
\hline$M_{r, l}, M_{r, r}$ & Rear-left and rear-right unsprung mass, respectively. & 45 & $\mathrm{~kg}$ \\
\hline$M_{s}$ & Seat Mass & 90 & $\mathrm{~kg}$ \\
\hline$M$ & Vehicle body mass & 1100 & $\mathrm{~kg}$ \\
\hline$I_{x}$ & Moment of inertia for pitch & 1848 & $\mathrm{~kg} \cdot \mathrm{m}^{2}$ \\
\hline$I_{y}$ & Moment of inertia for roll & 550 & $\mathrm{~kg} \cdot \mathrm{m}^{2}$ \\
\hline Cshy1 & Shyhook damper constant & -2500 & $\mathrm{~N} . \mathrm{sec} / \mathrm{m}$ \\
\hline
\end{tabular}

Table 1. Vehicle Suspension Parameters

and AFWNNC-2 use Mexican hat as wavelet in the consequent part and gaussian and triangular as membership function in the antecedent, respectively. AFWNNC-3 and AFWNNC-4 use Morlet as wavelet in the consequent part and gaussian and triangular as membership function in the antecedent, respectively. Two rules each having two membership functions have been used for simulation. For each AFWNN, 18 parameters have been adapted being the mean and variance of the antecedent part and translation, dilation and weights of the consequent part. Three types of road profiles have been examined to check the robustness

\begin{tabular}{|c|c|c|c|c|c|c|}
\hline Sr. No. & Control Algo. & Seat & \multicolumn{2}{|c|}{ Front } & \multicolumn{2}{|c|}{ Rear } \\
\cline { 4 - 7 } & & & Left & Right & Left & Right \\
\hline 1 & APID & 0.9 & 1 & 0.6 & 0.5 & 0.8 \\
2 & AFWNN-1 & 0.001 & 0.4 & 0.09 & 0.7 & 0.2 \\
3 & AFWNN-2 & 0.0054 & 0.08 & 0.09 & 0.08 & 0.09 \\
4 & AFWNN-3 & 0.003 & 0.08 & 0.007 & 0.009 & 0.008 \\
5 & AFWNN-4 & 0.003 & 0.0009 & 0.001 & 0.004 & 0.006 \\
\hline
\end{tabular}

Table 2. Learning rates ' $\gamma$ ' for controls

of the applied algorithms. These road profiles have been used in context of roll, pitch, heave and seat displacement and acceleration. Four controllers have been applied to each car tire and one has been taken for seat. The learning rates for each controller have been shown in Table 2. These values have been set for learning rates based on hit-and-trial keeping in view the fact that a positive change in the error rate leads to increase the value of ' $\gamma$ ' and vice versa. For simplicity of implementation the moment term has been neglected. 
The performance index used for evaluation of different algorithms is given by,

$$
I=\frac{1}{2} \int_{0}^{T}\left(Z_{P}^{T} Q Z_{P}\right) d t
$$

where, ' $Z_{p}$ ' is the vector for displacement or acceleration, ' $Q$ ' is the identity matrix. The Root Mean Square (RMS) value for displacement and acceleration of heave, pitch, roll and seat has been calculated by,

$$
\begin{aligned}
& z_{\text {disp. }}^{r m s}=\sqrt{\frac{1}{T} \int_{t=0}^{T}[h(t)]^{2}} \\
& \ddot{z}_{\text {acc. }}^{r m s}=\sqrt{\frac{1}{T} \int_{t=0}^{T}[\ddot{h}(t)]^{2}}
\end{aligned}
$$

Figure 5 shows different road profiles used for simulation.

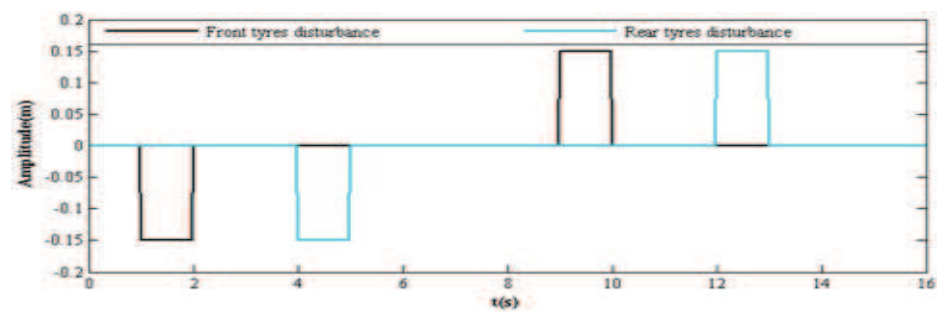

(a) Road profile-1

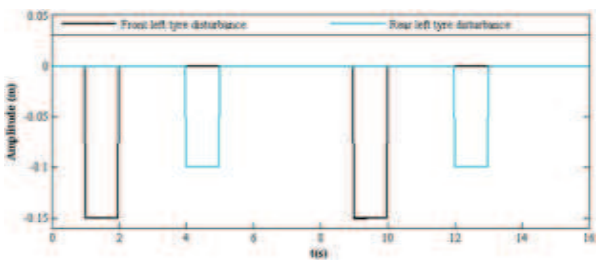

(b) Road profile-2 for front and rear left tires

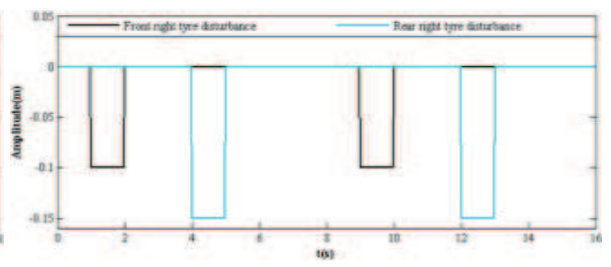

(c) Road profile-2 for front and rear right tires

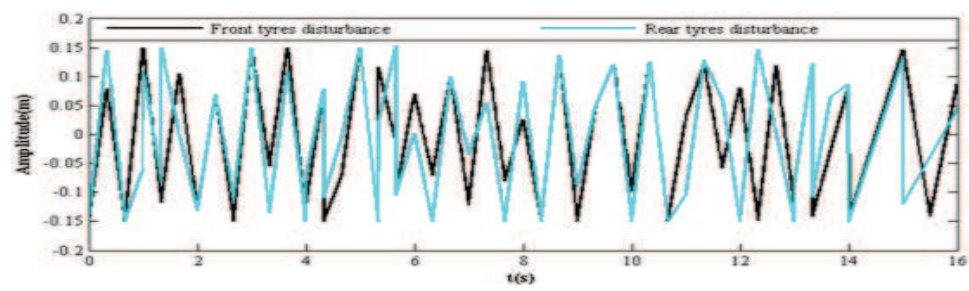

(d) Road profile-3

Fig. 5. (a) Road profile-1 (b) Road profile-2 (c) Road profile-3 


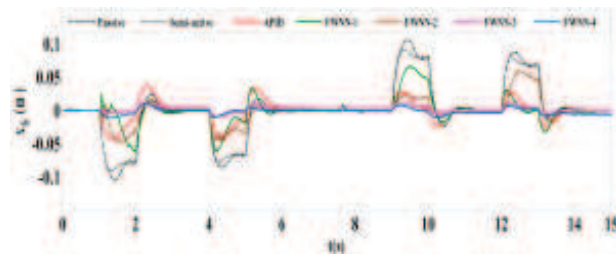

(a) Heave

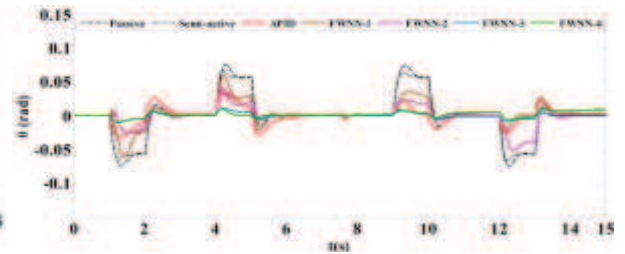

(b) Pitch

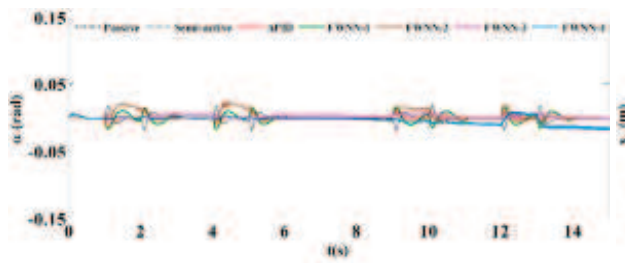

(c) Roll

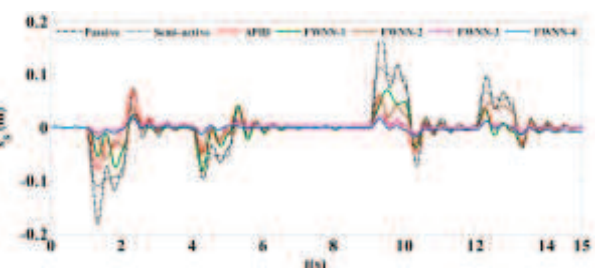

(d) Seat

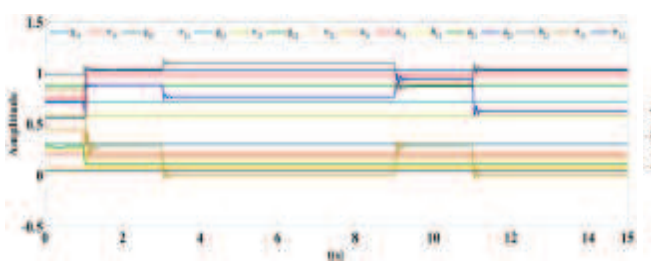

(e) Front left tire

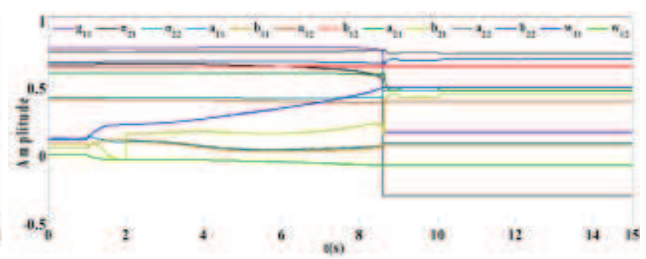

(f) Front right tire
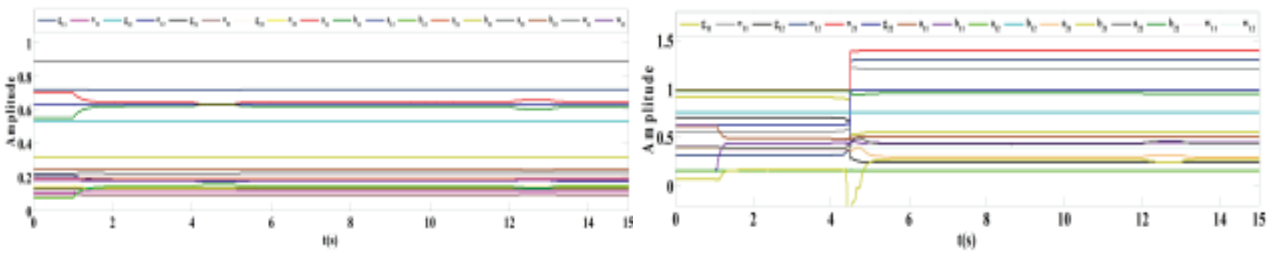

(g) Rear left tire

(h) Rear right tire

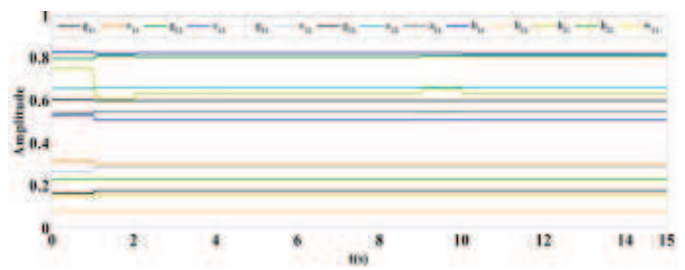

(i) Seat

Fig. 6. (a) Heave amplitude (b) Pitch amplitude (c) Roll amplitude (d) Seat amplitude (e)-(i) Update parameters for antecedent and consequent part of AFWNN-4 for all five controllers 


\subsection{Road profile-1}

Road profile-1 involves one pothole and one bump, each having duration of one second with a time delay of 8 secs., for front and rear tires. Mathematically, road profile- 1 is given by;

$$
z_{1}(t)= \begin{cases}-0.15 & 1 \leq t \leq 2 \text { and } 4 \leq t \leq 5 \\ 0.15 & 9 \leq t \leq 10 \text { and } 12 \leq t \leq 13 \\ 0 & \text { otherwise }\end{cases}
$$

i.e., the road profile contains a pothole and a bump of amplitudes $-0.15 m$ and $0.15 m$, respectively. This road profile is helpful to calculate heave of a vehicle. Figure 5(a) depicts the road profile-1. Figures 6(a)-(d) show the regulation results for heave, roll, pitch and seat displacement for active suspension as compared to passive and semi-active suspension. It is clear from the figures that there is improvement in the results for active suspension. The settling time has been reduced and the steady state response is improved. In case of heave and seat the passive control approaches the rattle space limits whereas AFWNN-4 has optimal results for all the four cases showing the least variation from steady state.

In passive and semi-active suspension suspension, the maximum values of displacements for heave is $0.106 \mathrm{~m}$ and $0.088 \mathrm{~m}$, for roll $0.016 \mathrm{~m}$ and $0.009 \mathrm{~m}$, for pitch is $0.075 \mathrm{~m}$ and $0.061 \mathrm{~m}$ and for seat is $0.15 \mathrm{~m}$ and 0.11 , respectively. Due to high nonlinear nature of AFWNN-4 these values get improved as $0.004 m, 0.006 m, 0.012 m$ and 0.02 for heave, roll pitch and seat, respectively.

Table3 shows the results for percent improvement and RMS values for displacement and acceleration, for road profile-1. It can be seen that maximum improvement has been achieved in case of heave with AFWNN-4. Figures 6(e)-(i) show the antecedent and consequent parameters variation for AFWNN-4 for all the five controls. Parameters variation for front and rear right tires is large whereas front and rear left tire has low parameters variation. It was found that the control effort by front and right tires was greater as compared to seat and the left side tires controls.

\subsection{Road profile-2}

Road profile- 2 has been taken as two potholes of different amplitudes as shown in Figures $5(\mathrm{~b})-(\mathrm{c})$. The road profile-2 is given as follows:

$$
z_{2}(t)= \begin{cases}-0.15 & 1 \leq t \leq 2 \text { and } 9 \leq t \leq 10 \\ -0.10 & 4 \leq t \leq 5 \text { and } 12 \leq t \leq 13 \\ 0 & \text { otherwise }\end{cases}
$$

Road profile- 2 involves two different potholes of amplitudes $-0.15 \mathrm{~m}$ and $-0.10 \mathrm{~m}$ for front and rear left and rear and front right, respectively. This road profile is very helpful for the calculation of pitch and roll of the vehicle.

Figures 7(a)-(d) reveal that APID shows satisfactory results whereas the result are very good in case of AFWNN-4. The maximum improvement has been found in case of roll for this road profile, which corresponds to the control of vehicle around horizontal axis. Figures 7(e)-(i) give the update parameters results for AFWNN-4 showing large variations for rear left and rear right tires. Table 4 shows the results for road profile- 2 in terms of percent improvement and RMS values of displacement and acceleration. The passive and semi-active suspension show poor performance in terms of passenger comfort and vehicle stability. 


\begin{tabular}{|c|c|c|c|c|c|c|c|}
\hline \multirow[t]{2}{*}{$\#$} & \multirow[t]{2}{*}{ Road Profile } & \multirow[t]{2}{*}{ Control Algo. } & \multirow[t]{2}{*}{ Performance Index } & \multicolumn{2}{|c|}{ RMS } & \multicolumn{2}{|c|}{ \% Improvement w.r.t. } \\
\hline & & & & Disp. & Acc. & Passive & Semi-active \\
\hline \multirow{7}{*}{1} & \multirow{7}{*}{ Heave } & Passive & 6.03515 & 0.0404 & 3.476 & - & - \\
\hline & & Semi-active & 5.3037 & 0.03729 & 3.2567 & - & - \\
\hline & & APID & 4.92835 & 0.0166 & 3.1395 & 70 & 62 \\
\hline & & AFWNN-1 & 4.6587 & 0.0158 & 3.0524 & 75 & 65 \\
\hline & & AFWNN-2 & 4.3854 & 0.0148 & 2.965 & 77 & 65 \\
\hline & & AFWNN-3 & 1.9529 & 0.00403 & 1.9763 & 93 & 89 \\
\hline & & AFWNN-4 & 1.8006 & 0.004 & 1.8977 & 94 & 93 \\
\hline \multirow{7}{*}{2} & \multirow{7}{*}{ Roll } & Passive & 1.6822 & 0.00545 & 1.8342 & - & - \\
\hline & & Semi-active & 1.4578 & 0.00443 & 1.7075 & - & - \\
\hline & & APID & 1.3194 & 0.00263 & 1.6244 & 53 & 05 \\
\hline & & AFWNN-1 & 0.7863 & 0.0021 & 1.2540 & 54 & 10 \\
\hline & & AFWNN-2 & 0.7213 & 0.0020 & 1.2011 & 57 & 15 \\
\hline & & AFWNN-3 & 0.4600 & 0.0031 & 0.9590 & 57 & 25 \\
\hline & & AFWNN-4 & 0.2494 & 0.0022 & 0.7063 & 62 & 35 \\
\hline \multirow{7}{*}{3} & \multirow{7}{*}{ Pitch } & Passive & 3.6786 & 0.0308 & 2.7122 & - & - \\
\hline & & Semi-active & 3.5407 & 0.0274 & 2.6610 & - & - \\
\hline & & APID & 2.9947 & 0.0094 & 2.4473 & 50 & 38 \\
\hline & & AFWNN-1 & 1.5545 & 0.01 & 1.7632 & 54 & 40 \\
\hline & & AFWNN-2 & 1.1381 & 0.01004 & 1.2011 & 69 & 62 \\
\hline & & AFWNN-3 & 0.9288 & 0.005 & 1.3629 & 80 & 73 \\
\hline & & AFWNN-4 & 0.7834 & 0.0041 & 1.2517 & 84 & 80 \\
\hline \multirow{7}{*}{4} & \multirow{7}{*}{ Seat } & Passive & 3.8449 & 0.04695 & 2.7726 & - & - \\
\hline & & Semi-active & 1.8379 & 0.04101 & 1.9168 & - & - \\
\hline & & APID & 0.8508 & 0.02 & 1.3043 & 55 & 28 \\
\hline & & AFWNN-1 & 0.7966 & 0.017 & 1.2621 & 70 & 49 \\
\hline & & AFWNN-2 & 0.6492 & 0.031 & 1.1319 & 72 & 51 \\
\hline & & AFWNN-3 & 0.066 & 0.0052 & 0.3631 & 87 & 77 \\
\hline & & AFWNN-4 & 0.0295 & 0.0039 & 0.2428 & 88 & 81 \\
\hline
\end{tabular}

Table 3. Performance Comparison for road profile-1

\subsection{Road profile-3}

Road profile-3 is white noise as shown in Figure 5(a).

$$
z_{3}(t)= \begin{cases}\sum_{i=1}^{N} A_{i} \sin \left(\Omega_{i} s-\Psi_{i}\right) & 0 \leq t \leq 16 \\ 0 & \text { otherwise }\end{cases}
$$

Where, value of ' $A_{i}$ ' is the road amplitude, ' $\Omega_{i}$ ' is the number of waves and ' $\Psi_{i}$ ' is the phase angle, $i=1,2, \ldots, N$ ranging from 0 to $2 \pi$.

The control problem is that the suspension travel should be $|z|$ less than $|\bar{z}|$ from the amplitude of disturbance i.e., $\pm 0.15 \mathrm{~m}$. The maximum displacement of the road profile is $\pm 0.15 m$. 


\begin{tabular}{|c|c|c|c|c|c|c|c|}
\hline \multirow[t]{2}{*}{$\#$} & \multirow[t]{2}{*}{ Road Profile } & \multirow[t]{2}{*}{ Control Algo. } & \multirow[t]{2}{*}{ Performance Index } & \multicolumn{2}{|c|}{ RMS } & \multicolumn{2}{|c|}{ \% Improvement w.r.t. } \\
\hline & & & & Disp. & Acc. & Passive & Semi-active \\
\hline \multirow{7}{*}{1} & \multirow{7}{*}{ Heave } & Passive & 4.2056 & 0.0339 & 2.9 & - & - \\
\hline & & Semi-active & 3.8635 & 0.09855 & 2.778 & - & - \\
\hline & & APID & 3.1469 & 0.01542 & 2.5087 & 57 & 36 \\
\hline & & AFWNN-1 & 2.9745 & 0.01397 & 2.439 & 60 & 47 \\
\hline & & AFWNN-2 & 3.0190 & 0.0144 & 2.453 & 80 & 72 \\
\hline & & AFWNN-3 & 1.2864 & 0.0036 & 1.604 & 83 & 78 \\
\hline & & AFWNN-4 & 1.1303 & 0.0040 & 1.503 & 87 & 82 \\
\hline \multirow{7}{*}{2} & \multirow{7}{*}{ Roll } & Passive & 1.7504 & 0.0099 & 1.8710 & - & - \\
\hline & & Semi-active & 1.5832 & 0.00679 & 1.7794 & - & - \\
\hline & & APID & 1.2140 & 0.00438 & 1.5582 & 36 & 25 \\
\hline & & AFWNN-1 & 0.8991 & 0.0022 & 1.3410 & 57 & 46 \\
\hline & & AFWNN-2 & 0.7176 & 0.0020 & 1.1980 & 63 & 46 \\
\hline & & AFWNN-3 & 0.5925 & 0.0024 & 1.0886 & 74 & 66 \\
\hline & & AFWNN-4 & 0.5011 & 0.0019 & 1.0010 & 95 & 92 \\
\hline \multirow{7}{*}{3} & \multirow{7}{*}{ Pitch } & Passive & 2.5485 & 0.0257 & 2.2575 & - & - \\
\hline & & Semi-active & 2.2184 & 0.0193 & 2.1063 & - & - \\
\hline & & APID & 1.9173 & 0.0119 & 1.9582 & 60 & 53 \\
\hline & & AFWNN-1 & 1.8417 & 0.0080 & 1.9190 & 50 & 10 \\
\hline & & AFWNN-2 & 1.6864 & 0.0067 & 1.8365 & 60 & 52 \\
\hline & & AFWNN-3 & 0.8484 & 0.0031 & 1.3026 & 78 & 74 \\
\hline & & AFWNN-4 & 0.8831 & 0.0024 & 1.3290 & 81 & 78 \\
\hline \multirow{7}{*}{4} & \multirow{7}{*}{ Seat } & Passive & 2.6620 & 0.0391 & 2.3011 & - & - \\
\hline & & Semi-active & 1.8148 & 0.03065 & 1.9049 & - & - \\
\hline & & APID & 0.7233 & 0.1850 & 1.2026 & 49 & 30 \\
\hline & & AFWNN-1 & 0.7014 & 0.1631 & 1.1731 & 69 & 40 \\
\hline & & AFWNN-2 & 0.7325 & 0.1432 & 1.2019 & 69 & 43 \\
\hline & & AFWNN-3 & 0.0533 & 0.0046 & 0.3265 & 83 & 69 \\
\hline & & AFWNN-4 & 0.0317 & 0.0024 & 0.2516 & 85 & 72 \\
\hline
\end{tabular}

Table 4. Performance comparison for road profile-2

The time delay between front and rear wheels is given by;

$$
\delta(t)=\frac{\left(s_{1}+s_{2}\right)}{V}
$$

Where, $s_{1}=1.2 \mathrm{~m}$ and $s_{2}=1.4 \mathrm{~m}$ are the values of distance between front and rear wheels and ' $V$ ' is the vehicle velocity. Figures 8(a)-(d) show the results for displacement for different car parameters for each algorithm. There is a performance degradation in case of AFWNN-2 for pitch. Figures 8(e)-(i) show the update parameters for consequent and antecedent part of AFWNN-4. Table 5 shows the performance comparison for road profile- 3 for different parameters. The best results have been obtained in case of AFWNN-4 for seat in this case. The minimum displacement for seat correspond to the passenger comfort which shows that AFWNN-4 gives optimal results for passenger comfort for comparatively rough road profiles. It can be seen that the performance difference between AFWNN-1 and AFWNN-2 is small as compared to that of AFWNN-1 and AFWNN-3 or AFWNN-4 which shows that incorporation of Morlet wavelet has improved the performance consistency, significantly. 


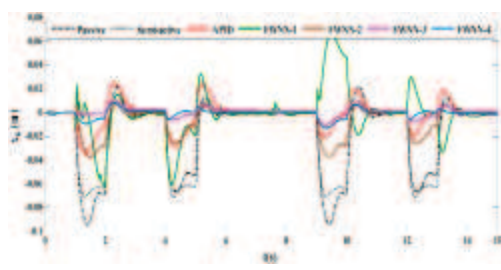

(a) Heave

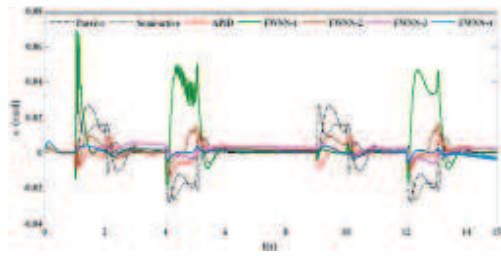

(c) Roll

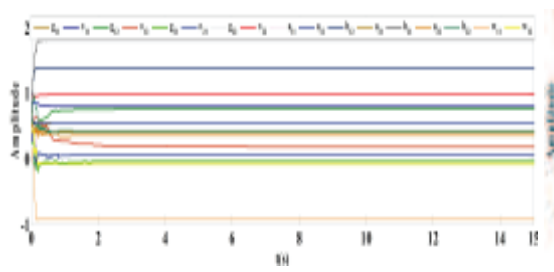

(e) Front left tire

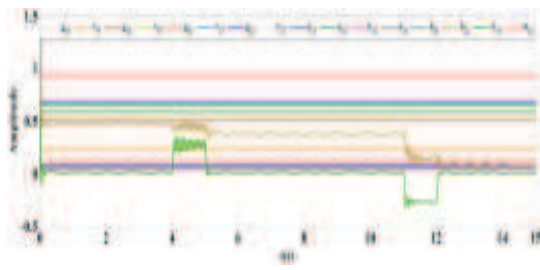

(g) Rear left tire

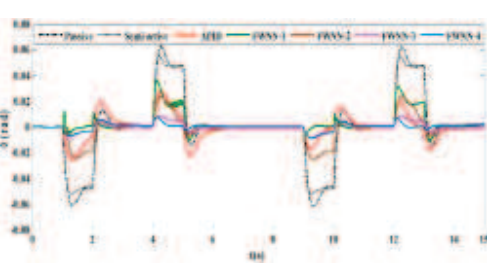

(b) Pitch

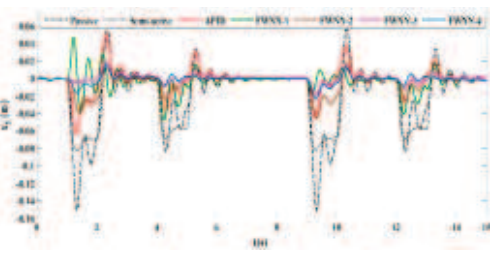

(d) Seat

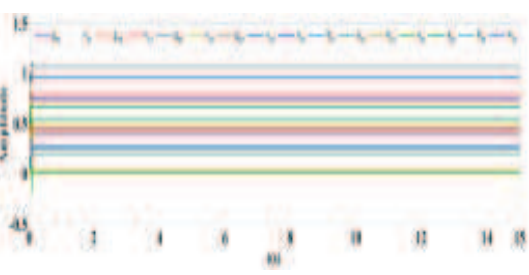

(f) Front right tire

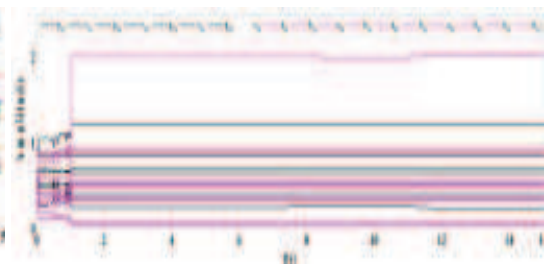

(h) Rear right tire

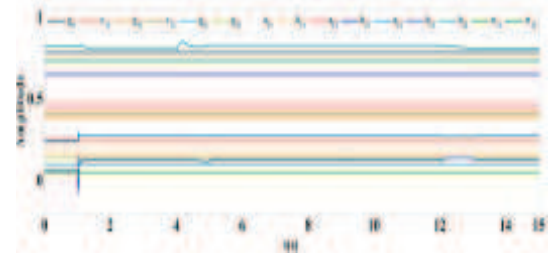

(i) Seat

Fig. 7. (a) Heave amplitude (b) Pitch amplitude (c) Roll amplitude (d) Seat amplitude (e)-(i) Update parameters for antecedent and consequent part of AFWNN-4 for all five controllers 


\begin{tabular}{|c|c|c|c|c|c|c|c|}
\hline \multirow[t]{2}{*}{$\#$} & \multirow[t]{2}{*}{ Parameters } & \multirow[t]{2}{*}{ Control Algo } & \multirow[t]{2}{*}{ Performance Index } & \multicolumn{2}{|c|}{ RMS } & \multicolumn{2}{|c|}{ \% Improvement w.r.t. } \\
\hline & & & & Disp. & Acc. & Passive & Semi-active \\
\hline \multirow{7}{*}{1} & \multirow{7}{*}{ Heave } & Passive & 34.0666 & 0.0682 & 8.254 & - & - \\
\hline & & Semi-active & 33.4707 & 0.06684 & 8.1815 & - & - \\
\hline & & APID & 14.2367 & 0.0239 & 5.336 & 64 & 53 \\
\hline & & FWNN-1 & 12.5589 & 0.02607 & 5.0117 & 64 & 55 \\
\hline & & FWNN-2 & 12.8224 & 0.0262 & 5.064 & 65 & 64 \\
\hline & & FWNN-3 & 8.0526 & 0.0318 & 4.013 & 79 & 73 \\
\hline & & FWNN-4 & 5.1264 & 0.00956 & 3.202 & 87 & 83 \\
\hline \multirow{7}{*}{2} & \multirow{7}{*}{ Roll } & Passive & 25.3794 & 0.0495 & 7.1243 & - & - \\
\hline & & Semi-active & 18.4609 & 0.0372 & 6.0762 & - & - \\
\hline & & APID & 13.0721 & 0.0223 & 5.1131 & 52 & 45 \\
\hline & & FWNN-1 & 0.1497 & 0.0190 & 4.5010 & 65 & 60 \\
\hline & & FWNN-2 & 7.6561 & 0.1903 & 3.9085 & 70 & 66 \\
\hline & & FWNN-3 & 5.0197 & 0.0430 & 3.1682 & 81 & 78 \\
\hline & & FWNN-4 & 3.9790 & 0.0219 & 2.8209 & 88 & 85 \\
\hline \multirow{7}{*}{3} & \multirow{7}{*}{ Pitch } & Passive & 3.8752 & 0.0216 & 2.7839 & - & - \\
\hline & & Semi-active & 3.1087 & 0.0192 & 2.4934 & - & - \\
\hline & & APID & 2.1505 & 0.0073 & 2.0739 & 40 & 44 \\
\hline & & FWNN-1 & 1.7559 & 0.0045 & 1.8760 & 59 & 56 \\
\hline & & FWNN-2 & 2.0279 & 0.0060 & 2.0739 & 50 & 45 \\
\hline & & FWNN-3 & 1.4126 & 0.166 & 1.6808 & 68 & 64 \\
\hline & & FWNN-4 & 0.7421 & 0.1403 & 1.2176 & 76 & 73 \\
\hline \multirow{7}{*}{4} & \multirow{7}{*}{ Seat } & Passive & 84.3201 & 0.1233 & 12.985 & - & - \\
\hline & & Semi-active & 60.0559 & 0.1098 & 10.9590 & - & - \\
\hline & & APID & 14.4606 & 0.0486 & 0.0486 & 65 & 35 \\
\hline & & FWNN-1 & 9.3490 & 0.02607 & 0.3142 & 72 & 45 \\
\hline & & FWNN-2 & 6.3870 & 0.0262 & 0.0221 & 73 & 46 \\
\hline & & FWNN-3 & 3.8223 & 0.0318 & 0.0278 & 80 & 67 \\
\hline & & FWNN-4 & 2.2046 & 0.0102 & 2.0998 & 90 & 92 \\
\hline
\end{tabular}

Table 5. Performance comparison for road profile-3 


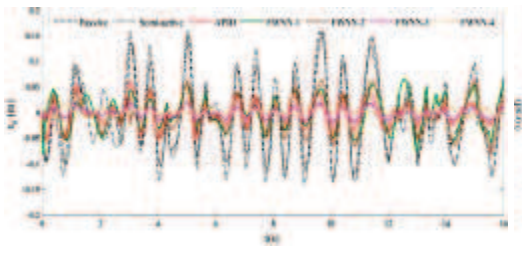

(a) Heave

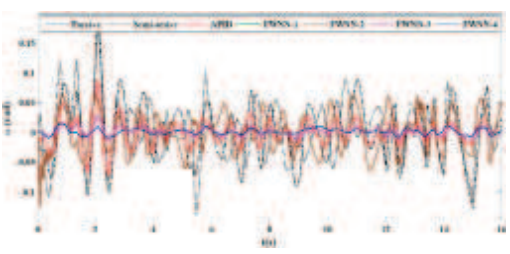

(c) Roll

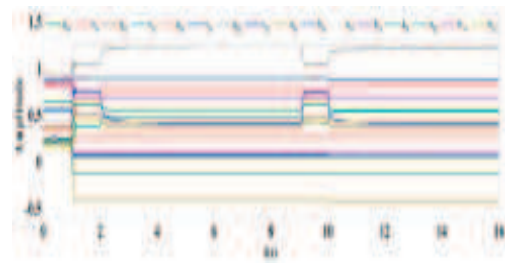

(e) Front left tire

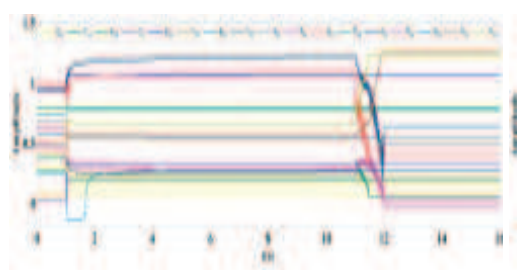

(g) Rear left tire

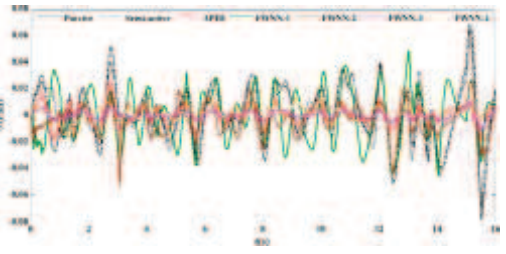

(b) Pitch

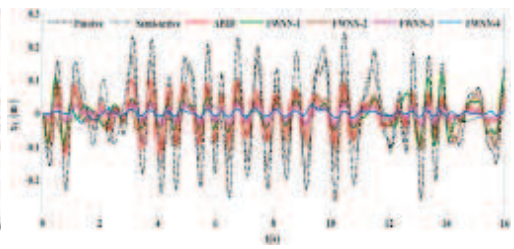

(d) Seat

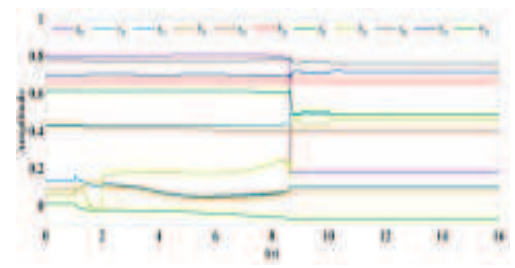

(i) Seat

Fig. 8. (a) Heave amplitude (b) Pitch amplitude (c) Roll amplitude (d) Seat amplitude (e)-(i) Update parameters for antecedent and consequent part of AFWNN-4 for all five controllers 


\section{Conclusion}

The detailed mathematical modeling of different adaptive softcomputing techniques have been developed and successfully applied to a full car model. The robustness of the presented techniques has been proved on the basis of different performance indices. Unlike, the conventional PID, the proposed algorithms have been compared with each other and APID controller. The simulation results and their analysis reveal that proposed AFWNNC gives better ride comfort and vehicle handling as compared to passive or semi-active and APID control. The performance of the active suspension has been optimized in terms of seat, heave, pitch and roll displacement and acceleration. The results show that AFWNNC-4 gives optimal performance for all rotational and translational motions of the vehicle persevering the passenger comfortability.

\section{References}

Abiyev, R. H. \& Kaynak, O. (2008). Fuzzy wavelet neural networks for identification and control of dynamic plants - a novel structure and comparative study, IEEE Transactions on Industrial Electronics 55(8): 3133-3140.

Adeli, H. \& Jiang, X. (2006). Dynamic fuzzy wavelet neural network model for structural system idetification, Journal of Structural Engineering 132(1): 102-112.

Ahmadian, M. \& Pare, C. (2000). A quarter-car experimental analysis of alternative semi-active control methods, Journal of Intellignet Material Systems and Structures 11(8): 604-612.

Al-Holou, N., Lahdhiri, T., Joo, D. S., Weaver, J. \& Al-Abbas, F. (2002). Sliding mode neural network inference fuzzy logic control for active suspension systems, IEEE Transactions on Fuzzy System 10(2): 234-236.

Banakar, A. \& Azeem, M. F. (2008). Artificial wavelet neural network and its application in neuro-fuzzy models, Applied Soft Computing 8: 1463-1485.

Barak, P. \& Hrovat, H. (1988). Application of the lqg approach to design of an automotive suspension for three-dimensional vehicle models, Proceedings of international conference of advanced suspensions, ImechE, London.

Bigarbegian, M., Melek, W. \& Golnaraghi, F. (2008). A novel neuro-fuzzy controller to enhance the performance of vehicle semi-active suspension systems, Vehicle System Dynamics 46(8): 691-711.

Billings, S. A. \& Wei, H. L. (2005). A new class of wavelet networks for nonlinear system identification, IEEE Trans. Neural Netw. 16(4): 862-874.

Cech, I. (1994). A full-car roll model of a vehicle with controlled suspension, Vehicle System Dynamics 23(1): 467-480.

Chalasani, R. M. (1986). Ride performance potential of active suspension system part 11: Comprehensive analysis based on a full car model, Proceedings of symposium on simulation and control of ground vehicles and transportation systems, ASME, AMD, Anaheim, CA.

Crolla, D. A. \& Abdel-Hady, M. B. A. (1991). Active suspension control: Performance comparisons using control laws applied to a full vehicle model, Vehicle System Dynamics 20(2): 107-120.

Esmailzadeh, E. \& Taghirad, H. D. (1996). Active vehicle suspensions with optimal state-feedback control, Journal of Mechanical Engineering Science 200(4): 1-18.

Hac, A. (1986). Stochastic optimal control of vehicles with elastic body and active suspension, Journal of Dynamic Systems, Measurement and Control 108(2): 106-110. 
Hac, A. (1987). Adaptive control of vehicle suspensions, Vehicle System Dynamics 16(2): 57-74. Hedrick, J. K. \& Butsuen, T. (1990). Invariant properties of automotive suspensions, Proceedings of the Institution of Mechanical Engineers. part D: Journal of Automobile Engineering 204(1): 21-27.

Heo, S. J., Park, K. \& Hwang, S. H. (2000). Performance and design consideration for continuosly controlled semi-active suspension systems, International Journal of Vehicle Design 23(3/4): 376-389.

Ho, D. W. C., Zhang, P.-A. \& Xu, J. (2001). Fuzzy wavelet networks for function learning, IEEE Transactions on Fuzzy Systems 9(1): 200-211.

Hrovat, D. (1982). A class of active lqg optimal actuators, Automatica 18(1): 117-119.

Huang, S. J. \& Lin, W. C. (2003). A self-organizing fuzzy controller for an active suspension system, Journal of Vibration Control 9(9): 1023-1040.

Kaleemullah, M., Faris, W. F. \& Hasbullah, F. (2011). Design of robust $h_{\infty}$, fuzzy and lqr controller for active suspension of a quarter car model, 4th International conference on mechatronics(ICOM), Kuala Lampur, Malaysia.

Krtolica, R. \& Hrovat, D. (1990). Optimal active suspension control based on a half-car model, Proceedings of the 29th IEEE conference on decision and control, Vol. 2, HI, USA, pp. 2238-2243.

Krtolica, R. \& Hrovat, D. (1992). Optimal active suspension control based on a half-car model: analytical solution, IEEE Transactions on Automatic Control 37(4): 528-532.

Kumar, M. S. (2008). Development of active suspension system for automobiles using pid controller, Proceedings of the World Congress on Engineering, Vol. 2, London, UK.

Lian, R. J., Lin, B. F. \& Sie, W. T. (Feb. 2005). Self-organizing fuzzy control of active suspension systems, International Journal of System Science 36(3): 119-135.

Lieh, J. \& Li, W. J. (1997). Adaptive fuzzy control of vehicle semi-active suspensions, Proceedings of ASME Dynamic Systems Control Division 61: 293-297.

Lin, J. \& Lian, R. J. (2008). Dsp-based self-organising fuzzy controller for active suspension systems, Vehicle System Dynamic 46(12): 1123-1139.

Lin, J. S. \& Kanellakopoulos, I. (1997). Nonlinear design of active suspension, IEEE Control Systems Megazine 17(3): 45-59.

Meld, R. C. (1991). Performance of lowbandwidth, semi-active damping concepts for suspension control, Vehicle System Dynamics 20(5): 245-267.

Meller, T. (1978). Self-energizing, hydro pneumatic leveling systems, SAE (780052).

Moran, A. \& Masao, N. (1994). Optimal active control of nonlinear vehicle suspensions using neural networks, JSME International Journal 37(4): 707-718.

Nicolas, C. F., Landaluze, ., Castrillo, E., Gaston, M. \& Reyero, R. (1997). Application of fuzzy logic control to the design of semi-active suspension systems, Proceedings of 6 th IEEE International Conference on Fuzzy Systems, Barcelona, Spain.

Oussar, Y. \& Dreyfus, G. (2000). Initialization by selection for wavelet network training, Neurocomputing 34: 131-143.

Rahmi, G. (2003). Active control of seat vibrations of a vehicle model using various suspension alternatives, Turkish Journal of Engineering and Enviormental Sciences 27: 361-373.

Rao, M. V. C. \& Prahlad, V. (1997). A tunable fuzzy logic controller for vehicle-active suspension system, Fuzzy Sets System 85: 11-21.

Ray, L. R. (1991). Robust linear-optimal control laws for active suspension system, Journal of Dynamic Systems, Measurement and Control 114(4): 592-599. 
Redfield, R. C. \& Karnopp, D. C. (1988). Optimal performance of variable component suspensions, Vehicle System Dynamics 17(5): 231-253.

Smith, M. C. (1995). Achievable dynamic response for automotive active suspension, Vehicle System Dynamics 24: 1-33.

Stein, G. J. \& Ballo, I. (1991). Active vibration control system for the driver's seat for off-road vehicles, Vehicle System Dynamics 20(2): 57-78.

Sunwoo, M., Cheok, K. C. \& Huang, N. (June 1991). Model reference adaptive control for vehicle active suspension systems, IEEE Transactions on Industrial Electronics 38(3): 217-222.

Thompson, A. G. \& Davis, B. R. (2005). Computation of the rms state variables and control forces in a half-car model with preview active suspension using spectral decomposition methods, Journal of Sound and Vibration 285(3): 571-583.

Thompson, A. G. \& Pearce, C. E. M. (1998). Physically realizable feedback controls for a fully active preview suspension applied to a half-car model, Vehicle System Dynamics 30(1): 17-35.

White-Smoke (2011).

URL: http://white-smoke.wetpaint.com/page/Heave, + Pitch, + Roll, + Warp+and $+Y a w$

Y. Chen, B. Y. \& Dong, J. (2006). Time-series prediction using a local linear wavelet neural network, Neurocomput. 69(4-6): 449-465.

Yester, J. L. \& Jr. (1992). Fuzzy logic control of vehicle active suspension, M.S. thesis, Electrical and Computer Engineering Department.

Yilmaz, S. \& Oysal, Y. (2010). Fuzzy wavelet neural network models for prediction and identification of dynamical systems, IEEE Transactions on Neural Networks 21(10): 1599-1609.

Yoshimura, T., Kume, A., Kurimoto, M. \& Hino, J. (2001). Construction of an active suspension system of a quarter car model using the concept of sliding mode control, Journal of Sound and Vibration 239(2): 187-199.

Yoshimura, T., Nakaminami, K., Kurimoto, M. \& Hino, J. (1999). Active suspension of passengers cars using linear and fuzzy-logic controls, Control Engineering Practice 7(1): 41-47.

Yue, C., Butsuen, T. \& Hedrick, J. K. (1988). Alternative control laws for automotive active suspensions, American Control Conference, IEEE, Atlanta, USA, pp. 2373-2378.

Zhang, J., Walter, G. G., Miao, Y. \& Lee, W. N. W. (1995). Wavelet neural networks for function learning, IEEE Trans. Signal Process 43(6): 1485-1497.

Zhang, Q. (1997). Using wavelet networks in nonparametric estimation, IEEE Trans. Neural Netw. 8(2): 227-236.

Zhang, Q. \& Benveniste, A. (1992). Wavelet networks, IEEE Trans. Neural Network 3(6): 889-898. 


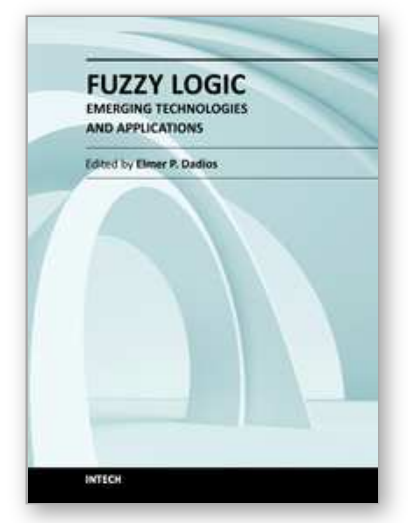

\author{
Fuzzy Logic - Emerging Technologies and Applications \\ Edited by Prof. Elmer Dadios
}

ISBN 978-953-51-0337-0

Hard cover, 348 pages

Publisher InTech

Published online 16, March, 2012

Published in print edition March, 2012

The capability of Fuzzy Logic in the development of emerging technologies is introduced in this book. The book consists of sixteen chapters showing various applications in the field of Bioinformatics, Health, Security, Communications, Transportations, Financial Management, Energy and Environment Systems. This book is a major reference source for all those concerned with applied intelligent systems. The intended readers are researchers, engineers, medical practitioners, and graduate students interested in fuzzy logic systems.

\title{
How to reference
}

In order to correctly reference this scholarly work, feel free to copy and paste the following:

Laiq Khan, Rabiah Badar and Shahid Qamar (2012). Adaptive Fuzzy Wavelet NN Control Strategy for Full Car Suspension System, Fuzzy Logic - Emerging Technologies and Applications, Prof. Elmer Dadios (Ed.), ISBN: 978-953-51-0337-0, InTech, Available from: http://www.intechopen.com/books/fuzzy-logic-emergingtechnologies-and-applications/adaptive-fuzzy-wavelet-nn-control-strategy-for-full-car-suspension-system

\section{INTECH}

open science | open minds

\author{
InTech Europe \\ University Campus STeP Ri \\ Slavka Krautzeka 83/A \\ 51000 Rijeka, Croatia \\ Phone: +385 (51) 770447 \\ Fax: +385 (51) 686166 \\ www.intechopen.com
}

\author{
InTech China \\ Unit 405, Office Block, Hotel Equatorial Shanghai \\ No.65, Yan An Road (West), Shanghai, 200040, China \\ 中国上海市延安西路65号上海国际贵都大饭店办公楼 405 单元 \\ Phone: +86-21-62489820 \\ Fax: $+86-21-62489821$
}


(C) 2012 The Author(s). Licensee IntechOpen. This is an open access article distributed under the terms of the Creative Commons Attribution 3.0 License, which permits unrestricted use, distribution, and reproduction in any medium, provided the original work is properly cited. 